\title{
A Numerical Wind Speed Simulation Model
}

\author{
J. V. Ramsdell \\ G. F. Athey \\ M. Y. Ballinger
}

September 1981

Prepared for the U.S. Department of Energy under Contract DE-AC06-76RLO 1830

Pacific Northwest Laboratory Operated for the U.S. Department of Energy by Battelle Memorial Institute 


\title{
NOTICE
}

This report was prepared as an account of work sponsored by the United States Government. Neither the United States nor the Department of Energy, nor any of their employees, nor any of their contractors, subcontractors, or their employees, makes any warranty, express or implied, or assumes any legal liability or responsibility for the accuracy. completeness or usefulness of any information, apparatus. product or process disclosed, or represents that its use would not infringe privately owned rights.

The views, opinions and conclusions contained in this report are those of the contractor and do not necessarily represent those of the United States Government or the United States Department of Energy.

\author{
PACIFIC NORTHWEST LABORATORY \\ operated by \\ BATTELLE \\ for the \\ UNITED STATES DEPARTMENT OF ENERGY \\ Under Contract DE-AC06-76RLO 1830
}

\author{
Printed in the United States of America \\ Available from \\ National Technical Information Service \\ United States Department of Commerce \\ 5285 Port Royal Road \\ Springfield. Virginia 22151
}

Price: Printed Copy \$

$\because$ Microfiche $\$ 3.00$

NTIS

-Pages Selling Price

$\begin{array}{lr}001-025 & \$ 4.00 \\ 026-050 & \$ 4.50 \\ 051-075 & \$ 5.25 \\ 076-100 & \$ 6.00 \\ 101-125 & \$ 6.50 \\ 126-150 & \$ 7.25 \\ 151-175 & \$ 8.00 \\ 176-200 & \$ 9.00 \\ 201-225 & \$ 9.25 \\ 226-250 & \$ 9.50 \\ 251-275 & \$ 10.75 \\ 276-300 & \$ 11.00\end{array}$


J. V. Ramsde11

G. F. Athey

M. Y. Ballinger

September 1981

Prepared for the U.S. Department of Energy under Contract DE-AC06-76RLO 1830 
, 


\section{SUMMARY}

A relatively simple stochastic model for simulating wind speed time series that can be used as an alternative to time series from representative locations is described in this report. The model incorporates systematic seasonal variation of the mean wind, its standard deviation, and the correlation speeds. It also incorporates systematic diurnal variation of the mean speed and standard deviation. To demonstrate the model capabilities, simulations were made using model parameters derived from data collected at the Hanford Meteorology Station, and results of analysis of simulated and actual data were compared.

Generally, the major features found in the analysis of real data can be identified in the analysis of the simulated data. The frequencies of high hourly and daily average wind speeds are underestimated slightly by the model. However, the model is useful in its current state for examining the spatial correlation of winds at potential wind energy conversion sites, and for evaluating techniques for adjusting climatological statistics derived from limited observations. 


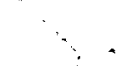




\section{CONTENTS}

SUMMARY

INTRODUCTION

MODEL DEVELOPMENT

THE MEAN WIND SPEED •

THE STANDARD DEVIATION OF THE RANDOM COMPONENT . . . . . 5

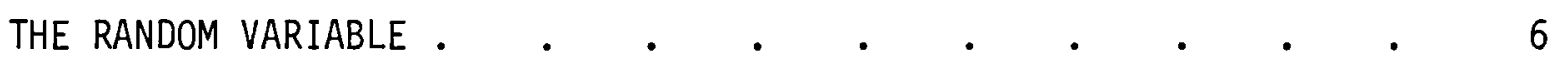

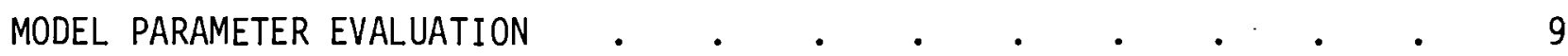

MODEL PERFORMANCE •

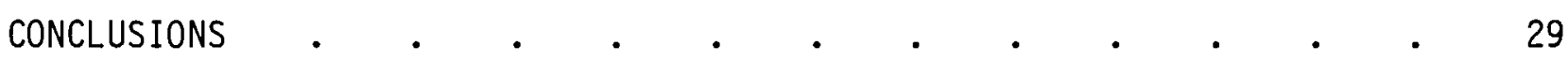

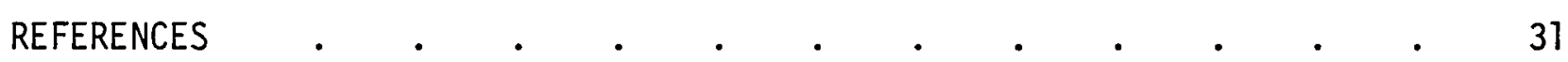

APPENDIX A $A$.

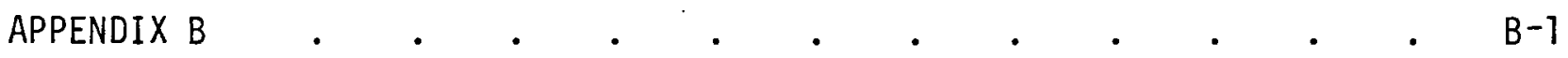

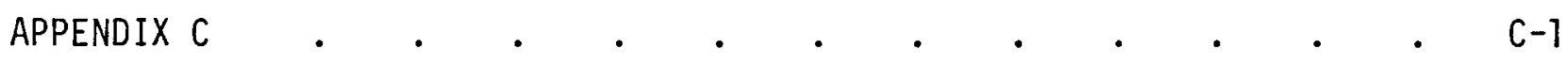




\section{FIGURES}

1. Comparison of the Distribution of Simulated Hourly Data with that for Actual Data and the Cumulative Frequencies for Standardized Gaussian and Rayleigh Distributions . . . 17

2. Persistence of Above Average Simulated Hourly Wind Speeds . . . 18

3. Cumulative Frequency Distribution of Daily Average Wind Speeds Computed from Simulated Hourly Speeds with

Comparative Data . . . . . . . . . . . . 20

4. Cumulative Frequency Distribution of Daily Average Wind Speeds Simulated Directly with Comparative Distributions . . . . . 21

5. Persistence of Above Average Simulated Daily Average Wind Speeds. .22

6. Autocorrelations of Simulated Daily Average Wind Speeds with Comparative Data . . . . . . . . . . . 24

7. Cumulative Frequency Distributions of Simulated Monthly Average Wind Speeds with Comparative Data . . . . . . 25

8. Autocorrelations of Simulated Monthly Average Wind Speeds with Comparative Data . . . . . . . . . . . 26

9. Persistence of Above Average Simulated Monthly Average Wind Speeds

\section{TABLES}

1. Monthly and Annual Hourly Average Wind Speeds (mph) for the HMS 50-Ft Level: $1955-70$

2. Approximate Phase Angles for Use with qualitative Wind Data . . . 13

3. Hourly Model Parameter Values Derived from HMS Data . . • . 15

4. Parameter Values for Daily and Monthly Average Wind Speed Models . . 19 


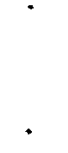


INTRODUCTION

Recent wind energy studies have demonstrated a general need for consistent, long-term wind speed time series data. This need is particularly apparent in the evaluation of wind energy conversion system economics for utilities, where the value of wind energy depends on the correlation between energy availability and demand. The current trend in economic studies is to use data from a "representative location" to incorporate realistic wind variability into economic models (e.g. JBF Scientific Corporation 1979; Electric Power Research Institute 1979; Kahn 1978; Sorensen 1978). Even the wind simulation model developed by Cliff et al. (1978) for use in studying the economics of dispersed arrays of wind energy conversion systems depends upon the availability of a time series from a representative location.

This dependence on a time series from a representative location has several drawbacks: among them are the problems attendant in finding a representative location and selecting a typical time series, and the problem of attempting to generalize from results based on a specially selected time series. A problem also arises if a representative location isn't found or doesn't have an adequate wind speed time series.

This report describes a relatively simple stochastic model for simulation of wind speed time series that can be used as an alternative to those from representative locations. Chou and Corotis (1981) have also developed a simulation model that does not require a time series for a representative location; however, its full implementation requires the user to specify values for 324 parameters. Our simulation model requires specification of at most 21 parameters.

Our simulation model is developed in the next section by treating wind speed as a locally stationary stochastic process in which random variability is superimposed upon a mean wind that includes systematic, deterministic seasonal and diurnal variations. The magnitude of the random fluctuations is allowed to undergo seasonal and diurnal variations, and seasonal variation of the autocorrelation is permitted. To test the model, wind data were simulated for the 50-foot level of the meteorological tower at Hanford, Washington. The simulated wind data and actual data from the tower were analyzed and the analyses are 
compared. Statistical measures used include cumulative frequency distributions, persistence of high wind speed events, and autocorrelations. Computer programs for the simulation model and evaluation of model parameters are presented in appendices. 


\section{MODEL DEVELOPMENT}

With sufficient past and current information and computer resources, the equations of fluid dynamics can be used to predict wind a short time into the future. However, such an approach to simulation of wind time series for wind energy studies is impractical both computationally and economically. It is more realistic to treat wind as a stochastic process and attempt to model the process in a way that incorporates the essential features of observed data.

As a basis for model development, we make the fundamental assumption that the wind at any location can be described in part by a long-term mean wind speed that is not a function of time. In practice this speed can only be estimated with observed data. The estimate improves as the period of observation increases so that a reasonably stable estimate results when 10 to 20 years' data have been obtained.

We also assume that there are no systematic variations with periods longer than a year. Thus we can concentrate on wind speed variations within a year.

These shorter variations of the wind are related to the development and passage of synoptic scale weather systems and local circulation patterns. As a result, we expect systematic seasonal and diurnal cycles to be present in the wind. These cycles may be affected by local topographic features. We do not attempt to define these relationships or the effect of topography.

Having placed these bounds on the model to be developed, we explore possible model forms. Most routine statistical analyses applied to random data assume that the data are representative of a stationary process. (The requirements for stationarity are discussed at length in texts on statistics and random variables, e.g., Bendat and Piersol 1971, and Papoulis 1965.) For a random process to be stationary in a wide sense, the expected value (mean) of the process must be independent of the time of observation and the autocorrelation in the process must be a function only of the separation between observations. For wind speed to be considered a stationary process, even in the wide sense, there should be neither seasonal nor diurnal variations in the 
mean. However, we have assumed both seasonal and diurnal variations in the driving force for the wind. Thus we are faced with development of a model for a nonstationary process.

Bendat and Piersol (1971) describe three types of nonstationarity in data and discuss possible methods for their treatment. The types of nonstationarity discussed include: time-varying mean value, time-varying mean square value and time-varying frequency structure. In general, wind speed time series can be expected to exhibit each of these features. Thus, we start with the following generic model for wind speed

$$
U(t)=F(t)+G(t) X(t)
$$

where:

$U(t)$ is the wind speed time series to be estimated

$F(t)$ is the time-varying mean speed

$G(t)$ is the time-varying standard deviation of the random fluctuations

$x(t)$ is a random variable with zero mean, unit variance and positive lag-one autocorrelation.

In the remainder of this section we will develop expressions for $F(t), G(t)$ and $x(t)$.

THE MEAN WIND SPEED

The way in which we specify the mean wind speed is one indication of the extent of our knowledge of the wind. If our knowledge is meager we may only be able to specify a single, long-term average. As our information increases we can begin to describe the variation of the mean in time. Both seasonal and diurnal variations can be expected.

On the basis of the factors, we will assume that the time-varying mean can be adequately described by a low-order Fourier series:

$$
F(t)=A_{0}+A_{1} \sin \left(\frac{2 \pi t}{8766}+\phi_{0}\right)+A_{2} \sin \left(\frac{2 \pi t}{24}+\phi_{2}\right) .
$$


$A_{0}$ is the long-term mean speed. $A_{1}$ and $A_{2}$ are the amplitudes of the seasonal and diurnal components of the mean variation, and $\phi_{0}$ and $\phi_{2}$ are phase angles needed to match the timing of wind characteristics at specific locations. If more detail is required in specification of the diurnal variations both $A_{2}$ and $\phi_{2}$ can be permitted to undergo seasonal variation. Thus, the last term in (2) may be expanded to:

$$
\left[A_{2}+A_{3} \sin \left(\frac{2 \pi t}{8766}+\phi_{1}\right)\right] \sin \left[\frac{2 \pi t}{24}+\phi_{2}+\phi_{3} \sin \left(\frac{2 \pi t}{8766}+\phi_{4}\right)\right]
$$

\section{THE STANDARD DEVIATION OF THE RANDOM COMPONENT}

The random component of the wind speed is modeled in two parts: a random variable with zero mean and unit variance, and a standard deviation that is used to scale the random variable. We will permit the standard deviation to vary in time as we did the mean.

Following the same logic that led to the Fourier series representation of the mean wind speed, we assume a Fourier representation for the variation of the standard deviation of the random component. Thus,

$$
G(t)=B_{0}+B_{1} \sin \left(\frac{2 \pi t}{8766}+\theta_{0}\right)+B_{2} \sin \left(\frac{2 \pi t}{24}+\theta_{2}\right)
$$

The parameters of (3) are analogous to those in (2), and again $B_{2}$ and $\theta_{2}$ can be expanded to include seasonal variations, i.e. the last term on the right becomes

$$
\left[B_{2}+B_{3} \sin \left(\frac{2 \pi t}{8766}+\theta_{1}\right)\right] \sin \left[\frac{2 \pi t}{24}+\theta_{2}+\theta_{3} \sin \left(\frac{2 \pi t}{8766}+\theta_{4}\right)\right]
$$

\section{THE RANDOM VARIABLE}

To a small extent we have already defined the random variable. We have required zero mean and unit variance (also standard deviation). The requirement 
for zero mean is necessary if we are to preserve the mean wind speed during simulation. If a non-zero mean were permitted for the random variable, the long-term mean of a simulated time series would not be equal to $A_{0}$. Similarly, if the random variable were not required to have unit variance, it would be difficult to match the wind speed variability of a specific location in simulation. Finally, there should be a positive correlation between consecutive random variables. This requirement is imposed in recognition of the role of synoptic conditions in determining winds.

The random variable $x(t)$ in ( 1$)$ is a single sample drawn from an as-yetunspecified probability distribution. To obtain the proper correlation between consecutive samples we will generate $X(t)$ from $X(t-1)$ in the following manner:

$$
X(t)=Y(t)+r X(t-1)
$$

where $Y(t)$ is drawn from a probability distribution with zero mean and unit variance and $r$ is the autocorrelation coefficient. The sequence $X(t)$ is a Markov series. If $Y(t)$ is drawn from a Gaussian distribution, $X(t)$ is also Gaussian.

However, wind speed distributions are generally not Gaussian. They tend to be positively skewed with wind speeds below average occurring more than $50 \%$ of the time and extremely high speeds occurring more frequently than expected from a Gaussian distribution. The Rayleigh distribution has frequently been used to model the distribution of wind speeds. The Rayleigh distribution is not directly suitable for $Y(t)$, because it has a non-zero mean and does not include negative values. These deficiencies can be corrected by a relatively simple transformation of variables. If $Y^{\prime}(t)$ is drawn from a Rayleigh distribution with mean $\bar{Y}$ and variance $S^{2}$, then the variable $Y(t)=\left[Y^{\prime}(t)-\bar{Y}\right] / S$ has zero mean, unit variance and is positively skewed. We will refer to this distribution as a standardized Rayleigh and denote it by $R(0,1)$.

The distribution of $X(t)$, when generated using the $R(0,1)$ variate $Y(t)$, is neither Rayleigh nor Gaussian. It varies as the autocorrelation coefficient 
varies from zero to one. For sma11 correlations, the distribution is approximately $R(0,1)$ and at high correlations the distribution tends toward Gaussian. The characteristics of the distribution $X(t)$ are described in more detail in Appendix A.

In a Gaussian Markov series, the autocorrelation between values decays exponentially with increasing separation. In the atmosphere, we would expect the autocorrelation to be a function of season. As a result, we model the autocorrelation as:

$$
r(t, \tau)=\exp [-\lambda(t) \cdot \tau]
$$

where $\lambda(t)$ is a decay constant that describes the time variation of $r$, and $\tau$ is the separation. Functionally, we will assume that

$$
\lambda(t)=\lambda_{0}+\lambda_{1} \sin \left(\frac{2 \pi t}{8766}+\gamma\right)
$$

and restrict our immediate consideration to the correlation between consecutive samples $(\tau=1)$.

Thus, the full wind speed simulation model requires specification of 21 parameters: 9 to describe the variation of the mean, 9 to describe the variation of the standard deviation of the distribution, and 3 to describe the variation of the autocorrelation. These parameters may be determined from available data, or they may be estimated from data available from nearby or similar locations. If the data available for parameter estimation are limited, it may be necessary to simplify the model. This can be accomplished by setting some of the parameters to zero. Setting $A_{1}, A_{2}, A_{3}, B_{1}, B_{2}, B_{3}$ and $\lambda_{1}$ to zero reduces the model to:

$$
U(t)=A_{0}+B_{0} X(t)
$$

which requires specifications of only three parameters, $A_{0}, B_{0}$ and $\lambda_{0}$. 


\section{MODEL PARAMETER EVALUATION}

A simulation model is useful only if model parameter values can be determined from available data. In this section we discuss the evaluation of parameters for the model just described. The order of evaluation is important. Parameters involved in the description of the mean should be evaluated first, the parameters for description of the variation of the standard deviation should be evaluated next, and those for description of the autocorrelation last. Further, it does not make sense to describe the variation of the standard deviation or the autocorrelation in more detail than is used for description of the mean. For example, if the description of the variation of the mean is limited to seasonal variation, no attempt should be made to account for the diurnal variation of standard deviation.

Evaluation of the parameters for description of the mean wind speed begins with estimation of the long-term mean and the seasonal variation of the mean. If the long-term mean is known, the value of $A_{0}$ is also known. Long-term mean speeds are readily available for many locations, or can be estimated to within about $10 \%$ accuracy with $90 \%$ confidence with a single year's measurements (Ramsde11, Houston and Wegley 1980). It is also relatively easy to obtain monthly average wind speeds. These averages can be used to estimate both the long-term mean and the seasonal variation of the mean. Bloomfield (1976) describes the determination of coefficients of a Fourier series. In our case we need only fit a first-order series with a period of one year to the monthly averages to obtain estimates of $A_{0}, A_{1}$ and $\phi_{0}$. Computer programs for analysis of data and time series simulation are presented in Appendices $B$ and $C$.

Evaluation of parameters to describe the diurnal variation of the mean follows the same format as the evaluation of the seasonal variation. Essentially the only differences are that data averaged by time of day are required, and the period of the variation is 24 hours instead of 1 year. The difference in periods between the seasonal and diurnal variation is sufficiently large that monthly average wind speeds for each hour of the day may be used in evaluating parameters for the diurnal variation without incurring a significant loss of information. Monthly average wind speeds, as a function of time of day, are 
contained in climatological publications including the Local Climatological Data (LCD) Monthly Summaries published by the National Climatic Center.

Table 1 contains a summary of 15 years' wind data for the 50-ft level at the Hanford Meteorology Station (HMS), Washington (Stone, Jenne and Thorp 1972). This table contains all of the data necessary to evaluate the 9 parameters in the model related to the mean wind speed. The last row and column in the table each contain summary data; the last row gives monthly averages and the last column gives annual averages by time of day. The speed in the bottom right-hand corner of the table is the long-term average. Thus, if we only need $A_{0}$, it can be read directly from the table. If we are only interested in the seasonal variation of the mean, we only need the last row. If we are interested in the seasonal and diurnal variation of the mean, but do not want to include the seasonal variation of the diurnal variation of the mean, we need only the last row and last column.

To determine the full set of parameters, we start with the January data and fit a first-order Fourier series to determine a mean and the amplitude and phase of the diurnal variation about the mean. This process is repeated for each month; we end up with 12 means, amplitudes and phase angles. Next we fit a first-order Fourier series to the 12 means. This gives us our estimates of $A_{0}, A_{1}$ and $\phi_{0}$. We then repeat the process with amplitudes to obtain $A_{2}, A_{3}$ and $\phi_{1}$. Finally we use the same procedure to get $\phi_{2}, \phi_{3}$ and $\phi_{4}$ from the phase angles.

Evaluation of the parameters for the standard deviation proceeds in the same manner as the evaluation of the parameters for the mean. If a table similar to Table 1 can be prepared, all nine parameters can be determined. Otherwise, it may be necessary to limit the variability modeled.

The total variability of the wind is composed of systematic and random components. The contribution of the individual components in the current model is:

$$
\left.\mathrm{S}^{2}=\mathrm{B}_{0}^{2}+\left(\mathrm{A}_{1}^{2}+\mathrm{A}_{2}^{2}+\mathrm{B}_{1}^{2}+\mathrm{B}_{2}^{2}\right) / 2+\mathrm{A}_{3}^{2}+\mathrm{B}_{3}^{2}\right) / 4
$$

where $S^{2}$ is the total wind speed variance. This relationship can be used to adjust the magnitude of $B_{0}$ as more detail is included in the model. 
TABLE 1. Monthly and Annual Hourly Average Wind Speeds (mph) for the HMS 50-Ft Level: 1955-70

Hour

Beginning

(PST)

J $I M \quad A \quad I \quad I \quad I \quad I \quad I$

$\begin{array}{llllllllllllll}00 & 6.2 & 6.9 & 8.2 & 8.7 & 9.0 & 9.9 & 9.8 & 9.1 & 7.9 & 6.6 & 6.1 & 6.1 & 7.9\end{array}$

$\begin{array}{llllllllllllll}01 & 6.1 & 6.7 & 8.0 & 8.4 & 8.5 & 9.1 & 9.0 & 8.3 & 7.3 & 6.3 & 6.1 & 6.0 & 7.5\end{array}$

$\begin{array}{llllllllllllll}02 & 6.0 & 6.7 & 7.9 & 8.0 & 7.9 & 8.4 & 8.1 & 7.5 & 7.0 & 6.0 & 5.8 & 6.0 & 7.1\end{array}$

$\begin{array}{llllllllllllll}03 & 5.9 & 6.6 & 7.5 & 7.5 & 7.6 & 7.7 & 7.5 & 6.9 & 6.8 & 6.0 & 5.7 & 5.8 & 6.8\end{array}$

$\begin{array}{llllllllllllll}04 & 5.8 & 6.6 & 7.3 & 7 . & 7.3 & 7.5 & 7.1 & 6.5 & 6.3 & 5.8 & 5.8 & 5.8 & 6.6\end{array}$

$\begin{array}{llllllllllllll}05 & 5.7 & 6.5 & 7.2 & 6.9 & 6.6 & 6.8 & 6.5 & 6.0 & 6.1 & 5.8 & 5.5 & 5.5 & 6.2\end{array}$

$\begin{array}{llllllllllllll}06 & 5.6 & 6.3 & 6.9 & 6.5 & 6.9 & 7.7 & 7.1 & 5.6 & 5.5 & 5.5 & 5.3 & 5.5 & 6.2\end{array}$

$\begin{array}{llllllllllllll}07 & 5.5 & 6.0 & 6.6 & 7.6 & 7.2 & 7.5 & 6.9 & 6.1 & 5.9 & 5.2 & 5.2 & 5.4 & 6.3\end{array}$

$\begin{array}{llllllllllllll}08 & 5.5 & 6.2 & 7.5 & 8.4 & 6.8 & 6.9 & 5.6 & 5.6 & 6.3 & 5.4 & 5.2 & 5.4 & 6.2\end{array}$

$\begin{array}{llllllllllllll}09 & 5.6 & 6.6 & 8.0 & 8.2 & 6.6 & 6.5 & 5.2 & 5.2 & 6.1 & 6.2 & 5.9 & 5.3 & 6.3\end{array}$

$\begin{array}{llllllllllllll}10 & 5.9 & 6.8 & 8.4 & 8.4 & 6.8 & 7.0 & 5.6 & 5.3 & 6.2 & 6.4 & 6.3 & 5.7 & 6.6\end{array}$

$\begin{array}{llllllllllllll}11 & 6.5 & 7.3 & 8.8 & 8.6 & 7.2 & 7.4 & 6.1 & 5.6 & 6.6 & 6.3 & 6.5 & 6.1 & 6.9\end{array}$

$\begin{array}{llllllllllllll}12 & 6.9 & 7.7 & 9.2 & 9.1 & 7.6 & 7.6 & 6.5 & 6.0 & 7.0 & 6.8 & 6.6 & 6.3 & 7.3\end{array}$

$\begin{array}{llllllllllllll}13 & 6.8 & 7.8 & 9.7 & 9.6 & 8.1 & 8.1 & 7.2 & 6.6 & 7.0 & 7.2 & 6.7 & 6.4 & 7.6\end{array}$

$\begin{array}{llllllllllllll}14 & 6.7 & 7.9 & 10.1 & 10.2 & 8.7 & 8.7 & 7.7 & 7.2 & 7.6 & 7.4 & 6.4 & 6.3 & 7.9\end{array}$

$\begin{array}{lllllllllllllll}15 & 6.2 & 8.0 & 10.2 & 10.5 & 9.4 & 9.4 & 8.3 & 7.8 & 8.1 & 7.5 & 6.3 & 6.0 & 8.1\end{array}$

$\begin{array}{llllllllllllll}16 & 6.2 & 7.6 & 10.4 & 11.1 & 9.9 & 10.5 & 9.1 & 8.5 & 8.5 & 7.3 & 6.1 & 6.0 & 8.4\end{array}$

$\begin{array}{llllllllllllll}17 & 6.4 & 7.4 & 9.6 & 11.3 & 10.7 & 12.0 & 10.3 & 9.5 & 8.8 & 7.4 & 6.5 & 6.2 & 8.8\end{array}$

$\begin{array}{llllllllllllll}18 & 6.7 & 7.7 & 9.4 & 10.9 & 11.2 & 12.9 & 11.4 & 10.3 & 9.1 & 8.0 & 6.4 & 6.2 & 9.2\end{array}$

$\begin{array}{llllllllllllll}19 & 6.8 & 7.6 & 9.5 & 10.9 & 11.3 & 13.0 & 12.1 & 11.2 & 9.8 & 7.9 & 6.4 & 6.1 & 9.4\end{array}$

$\begin{array}{llllllllllllll}20 & 6.6 & 7.6 & 11.0 & 11.0 & 11.4 & 13.0 & 12.8 & 11.8 & 9.7 & 7.6 & 6.4 & 6.0 & 9.5\end{array}$

$\begin{array}{llllllllllllll}21 & 6.4 & 7.3 & 9.1 & 10.5 & 11.5 & 12.8 & 13.2 & 12.0 & 9.3 & 7.4 & 6.2 & 6.0 & 9.3\end{array}$

$\begin{array}{llllllllllllll}22 & 6.1 & 7.3 & 8.4 & 9.9 & 10.6 & 12.1 & 12.3 & 11.0 & 8.7 & 7.1 & 6.2 & 6.0 & 8.8\end{array}$

$\begin{array}{llllllllllllll}23 & 6.1 & 7.2 & 8.3 & 9.1 & 9.8 & 10.9 & 10.7 & 9.9 & 8.1 & 6.8 & 6.2 & 6.1 & 8.3\end{array}$

$\begin{array}{llllllllllllll}\text { AVG } & 6.2 & 7.1 & 8.6 & 9.1 & 8.7 & 9.3 & 8.6 & 7.9 & 7.5 & 6.7 & 6.1 & 5.9 & 7.6\end{array}$ 
As an example of this use, assume that, initially, wind speed data are available in the form of frequency distributions for each month. These distributions provide sufficient information to estimate $A_{0}, A_{1}, B_{0}$ and $B_{1}$. They can also be combined to form a single frequency distribution that provides a direct estimate of $s^{2}$. If we gain additional information that permits us to model the diurnal variation of the mean speed, that variation must be included without increasing the total wind speed variance. $S^{2}, A_{1}$ and $B_{1}$ must all remain constant. Thus, we must decrease $B_{0}$. The new value of $B_{0}$ becomes

$$
B_{0}^{\prime}=\left[B_{0}^{2}-\left(A_{2}^{2}\right) / 2-\left(A_{3}^{2}\right) / 4\right]^{1 / 2}
$$

Similar corrections would be required if an initial modeling effort were made with the simple model given in (7) and then additional information permitted modeling the seasonal variation of the mean and the standard deviation.

The standard deviations needed to calculate the parameter values can be computed directly from wind speed observations, or they can be computed from wind speed frequency distributions. Wind speed frequency distributions are published in many places. The older issues of LCD Monthly Summaries (1964 and earlier) contain wind speed frequency distributions by time of day for each month, as well as composite distributions for the month. Annual wind speed frequency distributions are presented by state in the Wind Energy Resource Atlas (PNL-3195; 1980, 1981) prepared for the Department of Energy's Wind Energy Program, and Changery, Hodge and Ramsdell (1977) have prepared an index to summarized wind data available from the National Climatic Center in Asheville, North Carolina.

If available data will not support a quantitative evaluation of the phase angles required by the simulation model but the approximate times of wind speed maxima are known, the phase angles can be estimated from Table 2.

Unlike the evaluation of parameters for the variation of the mean and standard deviation, the evaluation of the parameters for the variation of the autocorrelation is not generally possible from standard wind data summaries. 
TABLE 2. Approximate Phase Angles for Use with Qualitative Wind Data

\begin{tabular}{|c|c|c|c|}
\hline $\begin{array}{l}\text { Time of Seasonal } \\
\text { maximum }\end{array}$ & $\begin{array}{l}\text { Time of Diurnal } \\
\text { maximum } \\
\end{array}$ & $\begin{array}{l}\text { Phase Angle } \\
\text { (degrees) }\end{array}$ & $\begin{array}{l}\text { Phase Angle } \\
\text { (radians) }\end{array}$ \\
\hline Jan 15 & 0100 & 75 & 1.3090 \\
\hline Feb 15 & 0300 & 45 & 0.7854 \\
\hline Mar 15 & 0500 & 15 & 0.2618 \\
\hline Apr 15 & 0700 & -15 & -0.2618 \\
\hline May 15 & 0900 & -45 & -07.854 \\
\hline Jun 15 & 1100 & -75 & -1.3090 \\
\hline Ju1 15 & 1300 & -105 & -1.8326 \\
\hline Aug 15 & 1500 & -135 & -2.3562 \\
\hline Sep 15 & 1700 & -165 & -2.8798 \\
\hline oct 15 & 1900 & 165 & 2.8798 \\
\hline Nov 15 & 2100 & 135 & 2.3562 \\
\hline Dec 15 & 2300 & 105 & 1.8326 \\
\hline
\end{tabular}

The difficulty in evaluation of the parameters arises in the product of timelagged wind speeds required for calculation of the autocorrelation. The autocorrelation for unit time lag can be computed from

$$
\bar{r}(t)=\left[\frac{\overline{U(t) U(t-1)-F(t) F(t-1)}}{G(t) G(t-1)}\right]
$$

where the overbar denotes a time average at time $t$, which may be a particular hour of the day in a given month, or an hour of the month, and it is understood that $\overline{x(t) x(t-1)}=\overline{r(t)}$. The dependence on $t$ is retained because we have assumed that the autocorrelation is subject to seasonal variations.

From (9) it is clear that the value of $r(t)$ is dependent upon the way in which $F(t)$ and $G(t)$ are described. If we know no more than the annual mean and standard deviation, then the autocorrelations computed from hourly wind speed observations may be significantly different than those computed if we know and remove the seasonal diurnal variations of the mean. Autocorrelations reported in the literature (e.g., Corotis, Sigl and Cohen 1977; Justus, 
Hargraves, Mikhail and Graber 1978; Justus, Mani and Mikhail 1979) should be used with caution until the user is satisfied that the systematic variation of the mean was properly treated in their computations.

Evaluation of the product of hourly wind speed observations can be accomplished in smart data loggers, but is not a commonly reported statistic. To be useful, this statistic must be tabulated by time of day, if diurnal variation is to be incorporated in the autocorrelation, or by month it the autocorrelation is to be limited to seasonal variations. Considering the relatively wide band of uncertainty about correlation coefficients computed from data with a limited number of degrees of freedom, we recommend that extension of the model to include diurnal variation of the autocorrelation coefficient not be considered.

If archived wind data must be used to compute the autocorrelation, it is necessary to properly account for the time lag between observations. Since we are primarily concerned with the simulation of a representative sequence of hourly observations, our basic time increment is 1 hour. The observations tabulated in recent LCD Monthly Summaries are taken at 3-hour intervals. If we wish to use them to estimate the autocorrelation at a time lag of 1 hour, we must account for the difference in observation frequency. To do this we can assume that the variations in $\lambda(t)$ are slow compared to the change in $\tau$ in (5). With this assumption, we compute $\lambda(t)$ as follows:

$$
\lambda(t)=-\ln [r(t, \tau)] / \tau
$$

where $\tau$ is 3 for observations reported 8 times a day, as is the current practice in the LCD Monthiy Summaries. 
MODEL PERFORMANCE

Simulation of hourly observations was conducted five times using models of increasing sophistication. The parameters for each of the simulations are given in Table 3. In model 1 , hourly observations were simulated without including any systematic variation in the mean, standard deviation or autocorrelation. In model 2, seasonal variations of the mean were added, etc. Model 5 includes seasonal and diurnal variation of the mean, and seasonal variation of the standard deviation and autocorrelation. When reference is made to an hourly wind speed simulation model without specifically indicating one of these models, model 5 can be assumed.

TABLE 3. Hourly Model Parameter Values Derived from HMS Data

\begin{tabular}{|c|c|c|c|c|c|}
\hline Parameter & Model 1 & Mode 12 & Model 3 & Mode 14 & Model 5 \\
\hline$A_{0}$ & 7.97 & 7.97 & 7.97 & 7.97 & 7.97 \\
\hline$A_{1}$ & & 1.62 & 1.62 & 1.62 & 1.62 \\
\hline$\phi_{0}$ & & -1.04 & -1.04 & -1.04 & -1.04 \\
\hline$A_{2}$ & & & 1.65 & 1.65 & 1.65 \\
\hline$A_{3}$ & & & 1.41 & 1.41 & 1.41 \\
\hline$\phi_{1}$ & & & -1.54 & -1.54 & -1.54 \\
\hline$\phi_{2}$ & & & 0.311 & 0.311 & 0.311 \\
\hline$\phi_{3}$ & & & 2.96 & 2.96 & 2.96 \\
\hline$\phi_{4}$ & & & -2.37 & -2.37 & -2.37 \\
\hline $\mathrm{B}_{0}$ & 5.87 & 5.64 & 5.39 & 5.34 & 5.34 \\
\hline$B_{1}$ & & & & 0.619 & 0.619 \\
\hline$\theta_{0}$ & & & & 0.688 & 0.688 \\
\hline$\lambda_{0}$ & -0.477 & -0.477 & -0.477 & -0.477 & -0.477 \\
\hline$\lambda_{1}$ & & & & & 0.158 \\
\hline$\gamma$ & & & & & -1.419 \\
\hline
\end{tabular}

The models all reproduced those systematic variations that were incorporated within the limits of the random variability introduced in the simulations. There were no noticeable changes in phase of either the diurnal or seasonal variations. 
The frequency distributions for hourly data simulated with the five models were essentially identical. Figure 1 shows the cumulative distribution for the simulated data and compares it with the cumulative distribution for data from Hanford. The cumulative distribution is also compared with the standardized Rayleigh and Gaussian distributions. The actual wind speed distribution is reasonably approximated by the $\mathrm{R}(0,1)$ distribution, although it has a larger frequency of occurrence of extremely high speeds than would be expected from the $R(0,1)$ distribution. The distributions of simulated speeds match the $R(0,1)$ distribution at speeds above the mean, and consequently the frequencies of high simulated speeds are lower than the observed frequencies. The differences are somewhat exaggerated by the expanding frequency scale used in the figure. The actual data indicate that standardized wind speeds less than about 3 occur about $98.9 \%$ of the time, while the model has them occurring about $99.6 \%$ of the time. Standardized speeds are determined from the actual speeds by removing the mean and dividing by the standard deviation. They are used exclusively in the remainder of this discussion.

The persistence of high wind speed events in the simulated data is described in Figure 2 for three standardized wind speeds. It does not appear that the number of parameters used in the model has much effect on the frequency of short-term persistence events. As the length of the events increases, however, model complexity becomes a factor. The frequency of occurrence of 12-hour events in which the speed exceeds 0.5 was a factor of 3 larger for model 5 than it was for model 1.

It appears that after an initially rapid decay, the decrease in frequency tends to become exponential. Corotis, Sigl and Klein (1978) have previously reported an exponential model giving good fits to persistence frequencies. They have also described a power law model. Sigl, Corotis and Won (1979) also present a power law model.

The simulated hourly data were combined to approximate daily wind speed averages. The cumulative distribution of averages thus formed is compared with the distribution of observed daily averages in Figure 3. The differences between the distributions are significant. The simulated daily averages show an approximately $N(0,1)$ distribution, while the distribution of the actual averages is more 


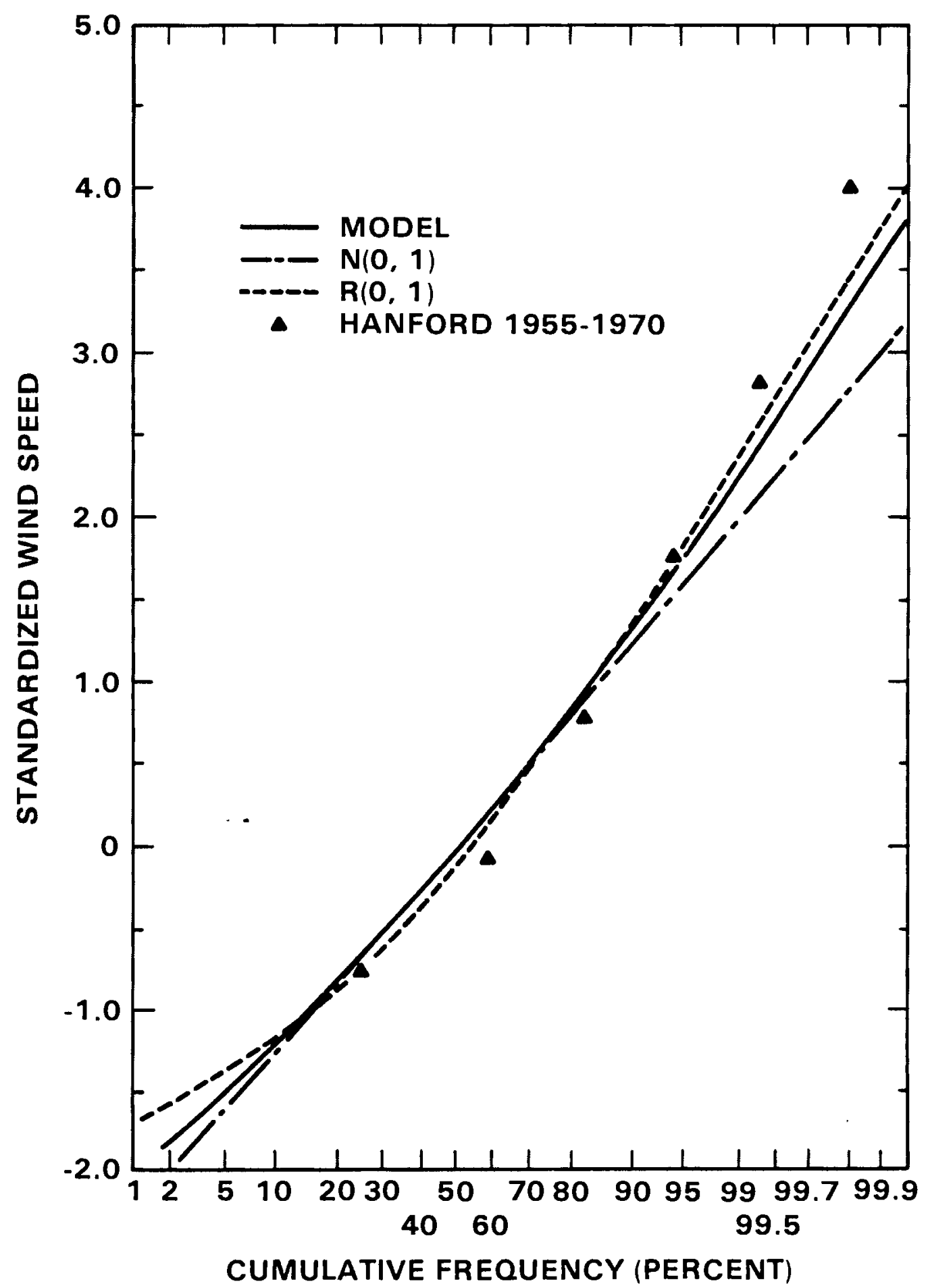

FIGURE 1. Comparison of the Distribution of Simulated Hourly Data with that for Actual Data and the Cumulative Frequencies for Standardized Gaussian and Rayleigh Distributions 


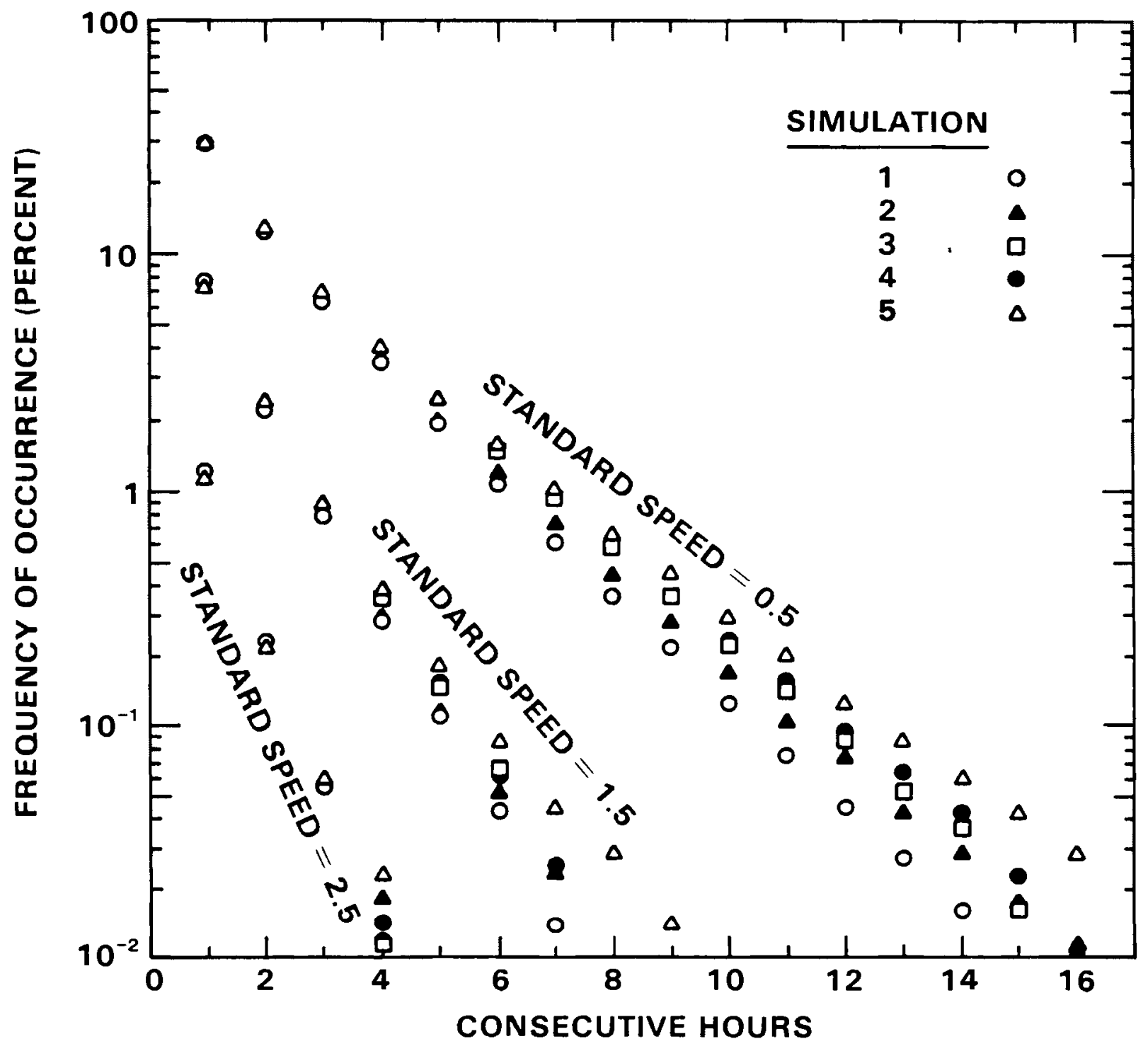

FIGURE 2. Persistence of Above Average Simulated Hourly Wind Speeds 
nearly $R(0,1)$. When monthly averages of the simulated hourly data were formed there were similarly large differences between simulated and actual cumulative distributions.

The model was rerun in an attempt to simulate the daily average wind speeds directly, and a modified model was run to simulate the monthly average speeds. Parameters used in these models are listed in Table 4. In the modified model, the random variate was assumed to have an $\mathrm{N}(0,1)$ distribution rather than an $R(0,1)$ distribution. In other respects the modified model was unchanged from that used for the daily and hourly wind speed simulations.

TABLE 4. Parameter Values for Daily and Monthly Average Wind Speed Models

\begin{tabular}{ccc} 
Parameter & $\begin{array}{c}\text { Daily } \\
\text { Average }\end{array}$ & $\begin{array}{c}\text { Monthly } \\
\text { Average }\end{array}$ \\
\cline { 1 - 2 } $\mathrm{A}_{0}$ & 7.88 & 7.68 \\
$\mathrm{~A}_{1}$ & 1.68 & 1.63 \\
$\phi_{0}$ & -0.948 & -0.998 \\
${ }^{\mathrm{B}_{0}}$ & 3.56 & 1.04 \\
${ }^{\mathrm{B}}{ }_{1}$ & 0.700 & 0.390 \\
${ }_{0}$ & 0.975 & 1.167 \\
${ }_{0}$ & -1.458 & -1.510 \\
$\lambda_{1}$ & 0.232 & \\
$\gamma$ & 1.050 &
\end{tabular}

Figure 4 shows the distribution for the results of the direct simulation of daily averages along with the cumulative distribution of the observed data. The improvement of direct simulation of daily averages over averaging simulated hourly speeds is significant.

The persistence of days with wind speeds above the mean is shown in Figure 5. Simulating daily averages directly and averaging simulated hourly data both give good approximations to the observed persistence frequencies. The comparison is particularly good for a standardized wind speed of 0.5 . For the higher speeds, the frequencies are slightly underestimated. It should be noted that these statistics are for end-to-end 24-hour periods. 


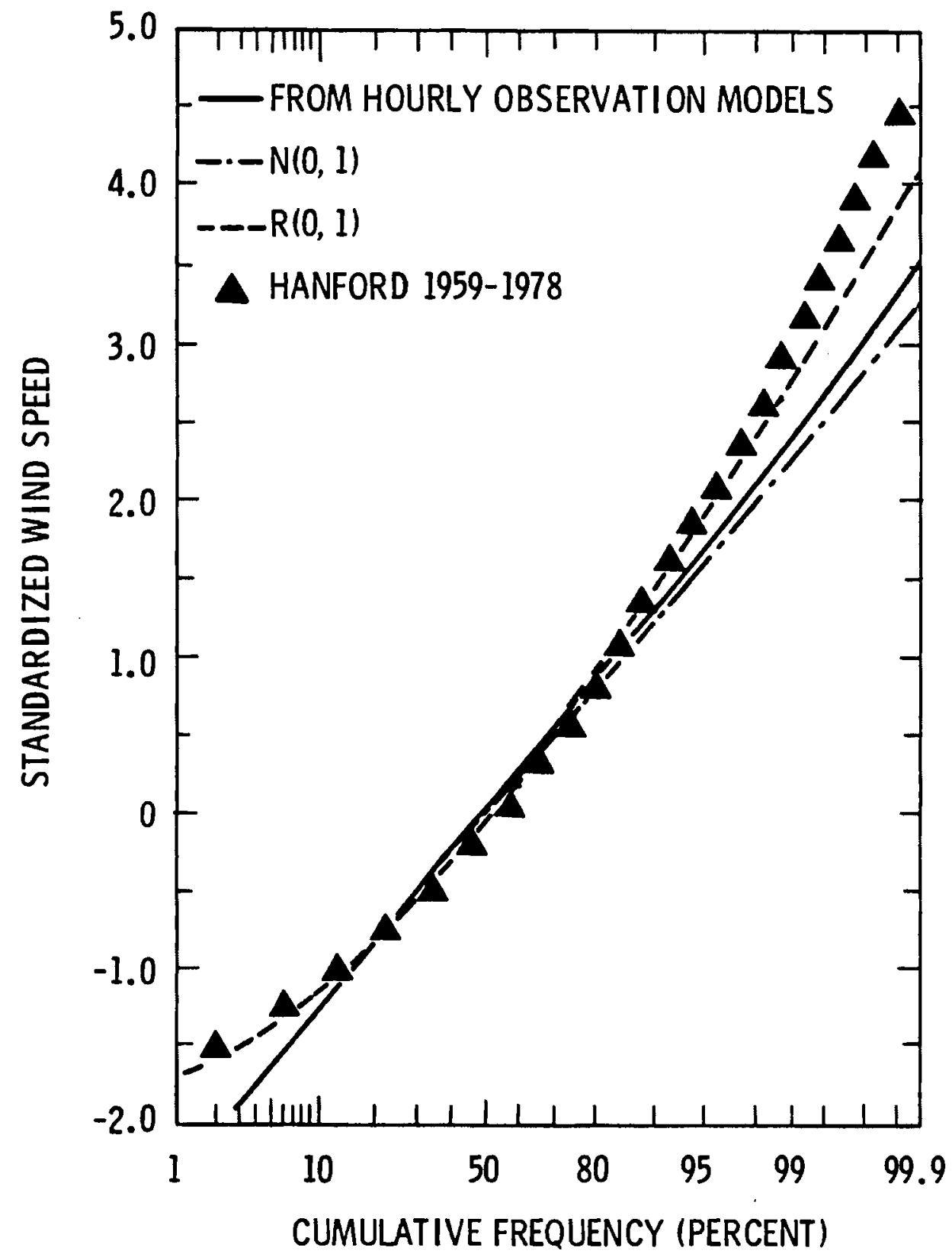

FIGURE 3. Cumulative Frequency Distribution of Daily Averaged Wind Speeds Computed from Simulated Hourly Speeds with Comparative Data 


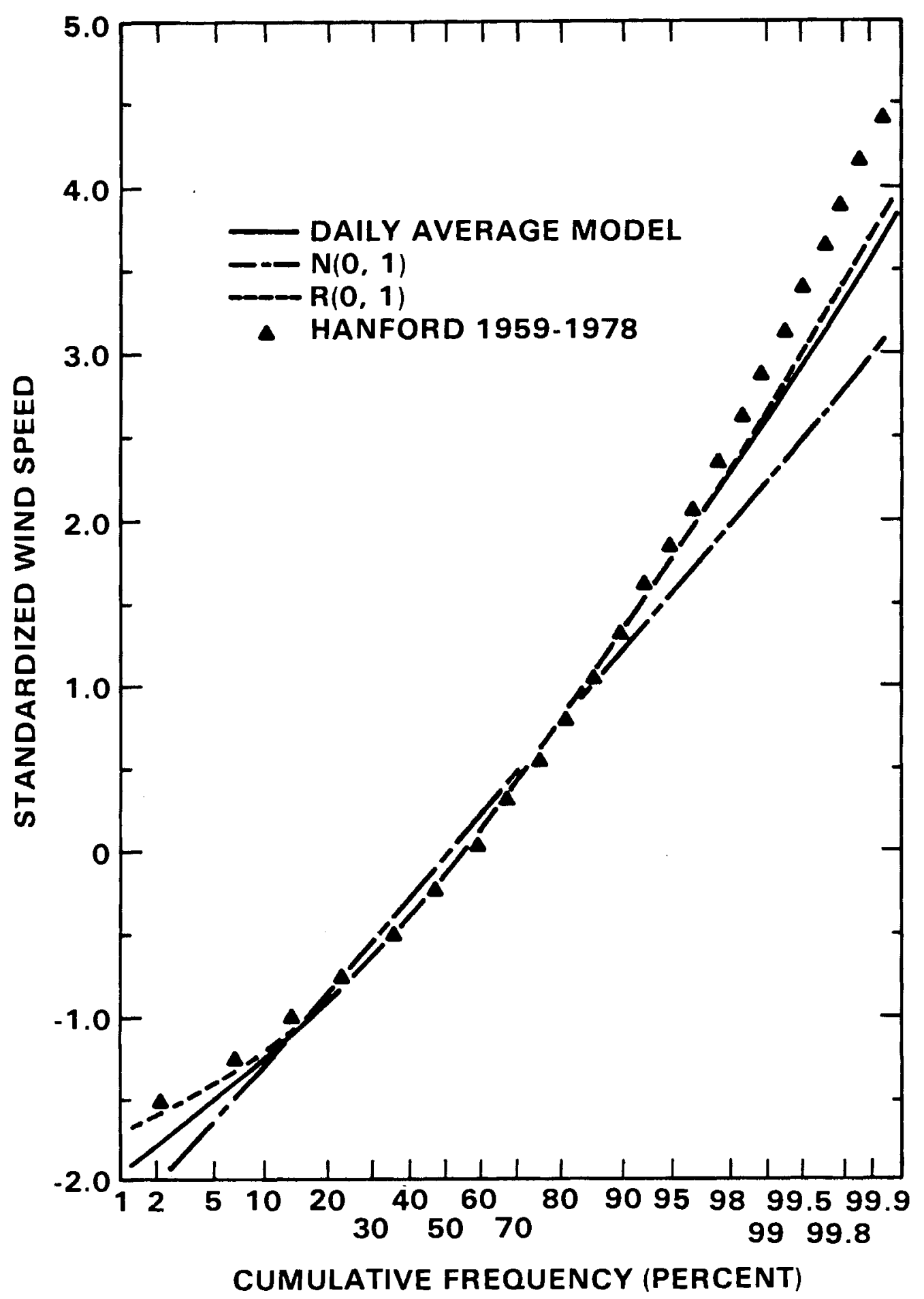

FIGURE 4. Cumulative Frequency Distribution of Daily Average Wind Speeds Simulated Directly with Comparative Distributions 


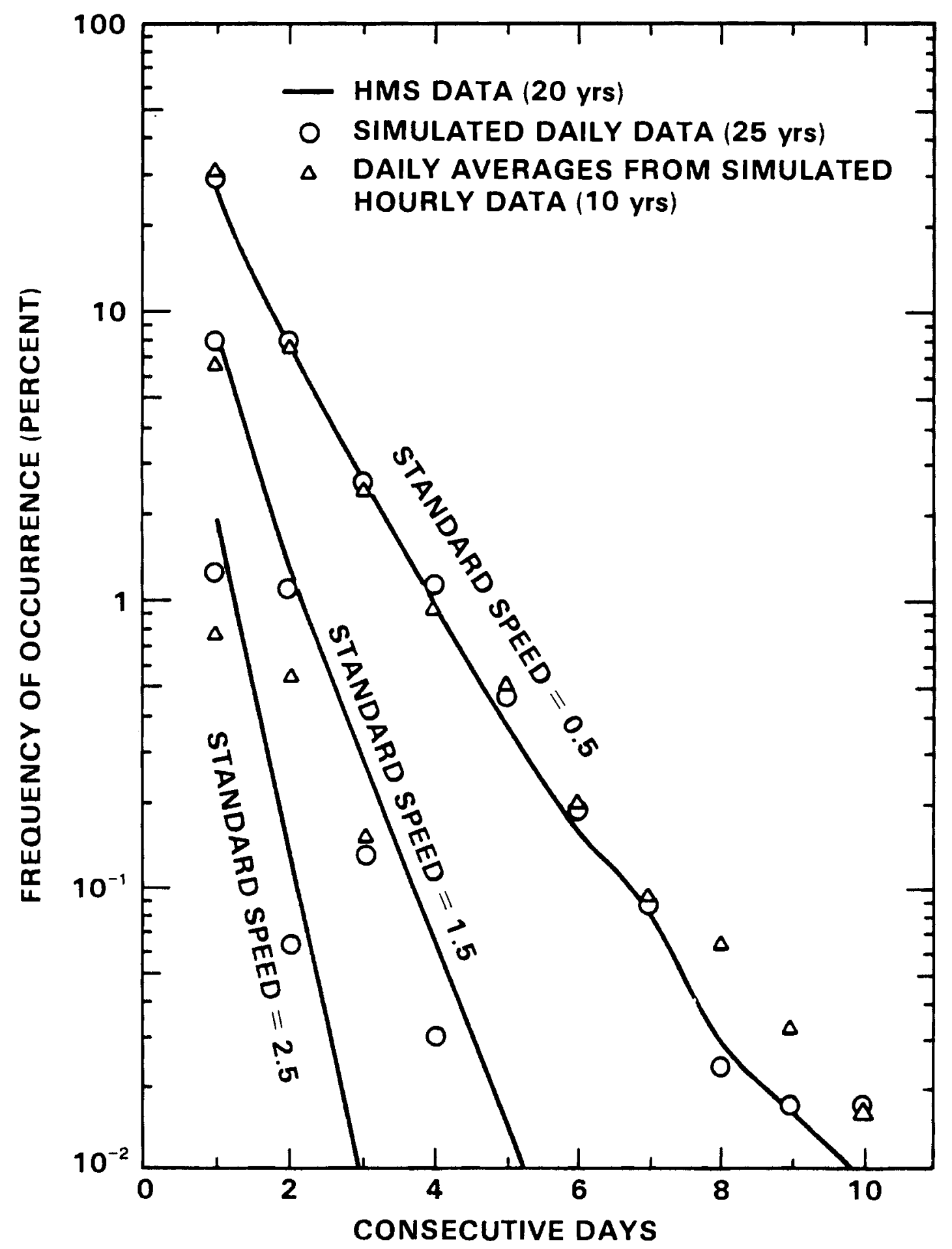

FIGURE 5. Persistence of Above Average Simulated Daily Average Wind Speeds 
The autocorrelation of daily average wind speeds is shown in Figure 6 . The direct simulation of daily averages is again shown to provide results that more closely match the actual data than averaging simulated hourly data. The figure also shows the effect of the seasonal trend on the autocorrelation. It is responsible for essentially all of the correlation in the daily averages derived from simulated hourly data and for the correlation for lags of 3 days or more in the daily averages simulated directly.

Cumulative frequency distributions for monthly average speeds are compared in Figure 7. Direct simulation of monthly averages gives an extremely good fit to the actual data. Averaging simulating and daily data does not give an adequate fit to the cumulative distribution of observed monthly averages. By averaging the hourly data most of the random variability introduced in the simulation is eliminated. As a result, the remaining variability is from the systematic seasonal variation of the mean. The cumulative frequency distribution shown for the monthly averages formed from the hourly data is close to the sigmoid curve that would be expected from the distribution of points on a sinusoid.

The autocorrelations of the monthly average data shown in Figure 8 further demonstrate the decrease in random variability associated with averaging the simulated data. The autocorrelation of the hourly data closely follows the cosine curve that represents the autocorrelation of points along a sinusoid. The autocorrelation of monthly averages simulated directly follows the autocorrelation of the data, and the autocorrelation of the averaged daily data falls between the other two sets.

Finally, Figure 9 shows the persistence statistics for the monthly average speeds. 


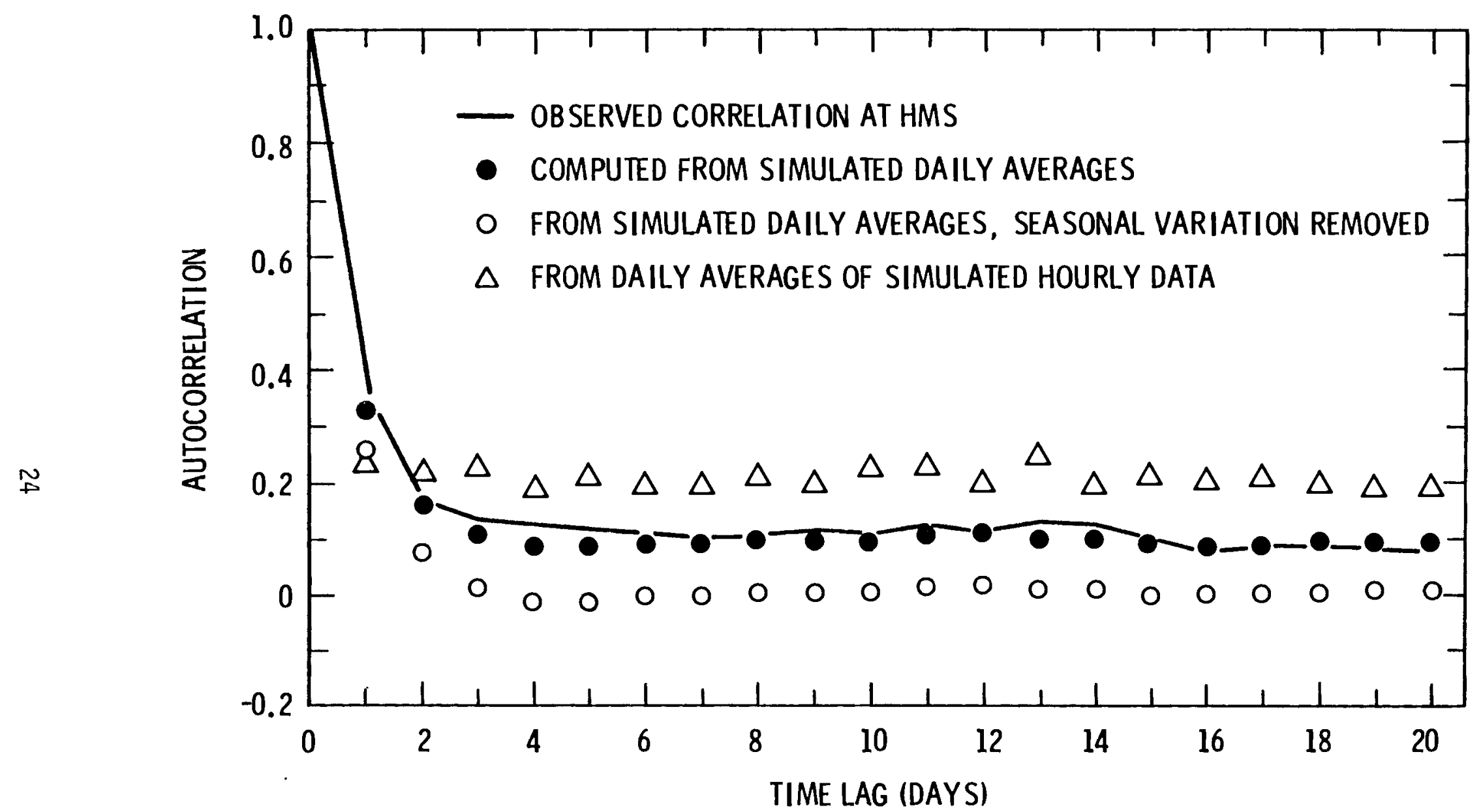

FIGURE 6. Autocorrelations of Simulated Daily Average Wind Speeds with Comparative Data 


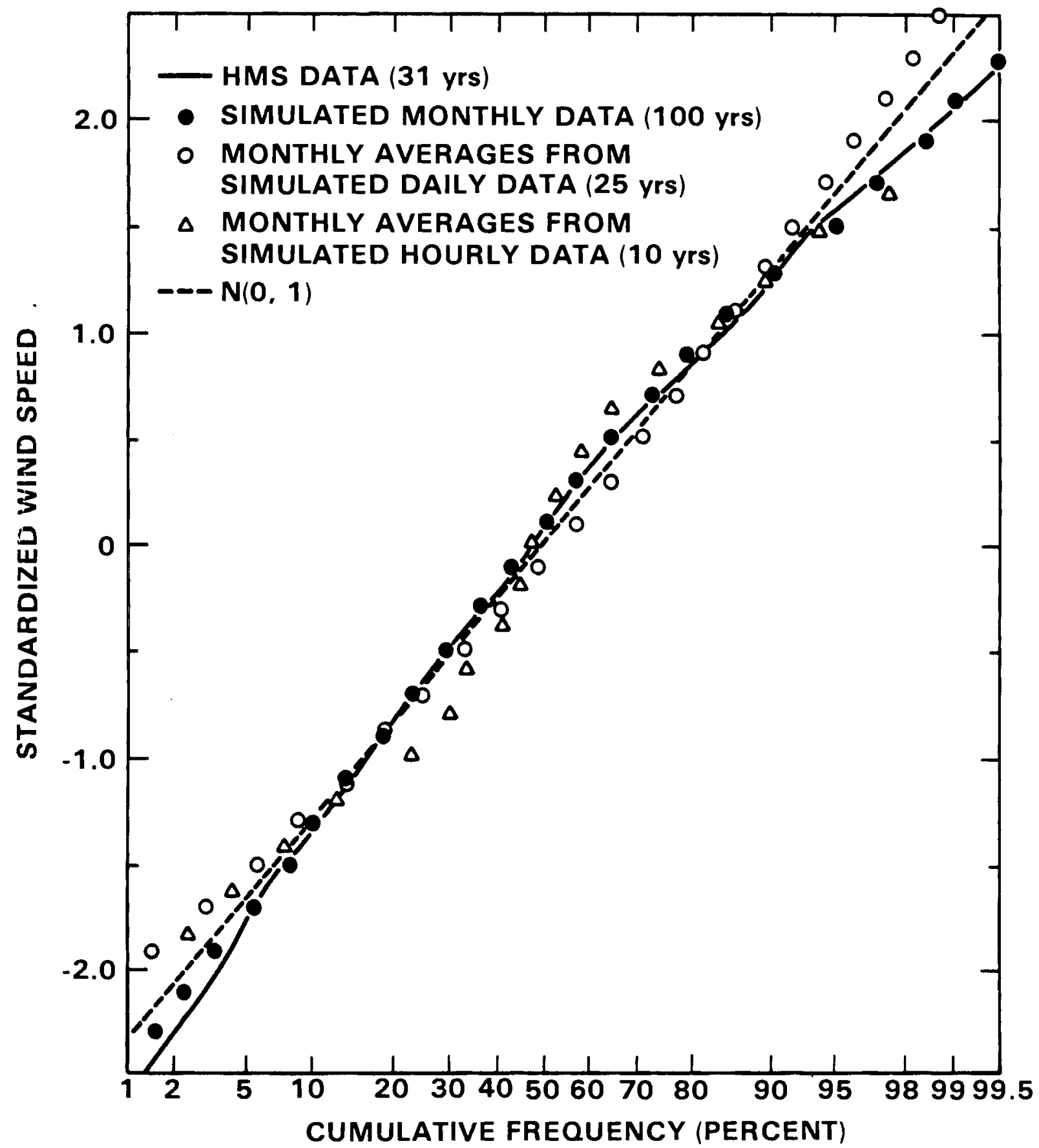

FIGURE 7. Cumulative Frequency Distributions of Simulated Monthly Average Wind Speeds with Comparative Data 


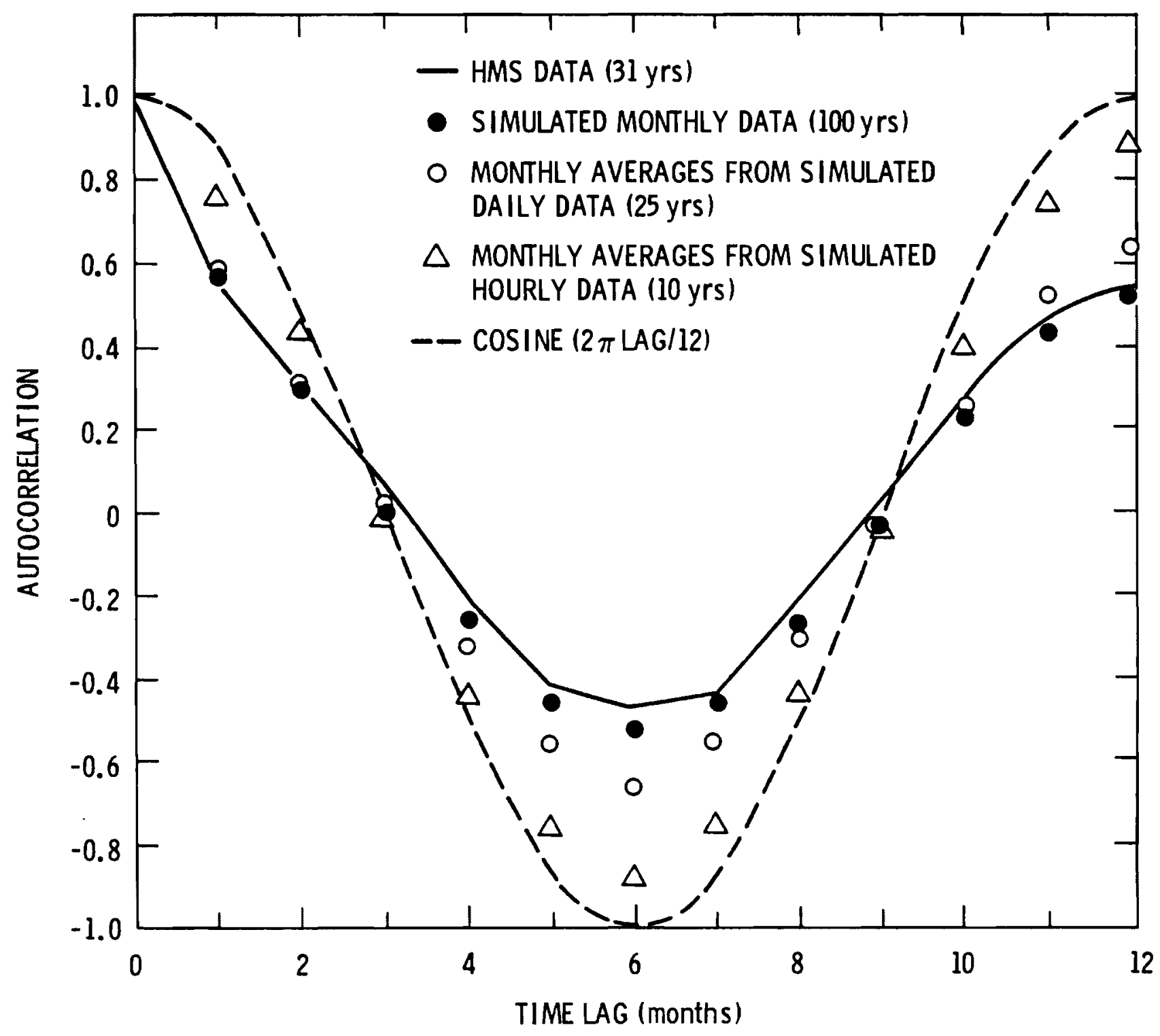
FIGURE 8. Autocorrelations of Simulated Monthly Average Wind Speeds with
Comparative Data 


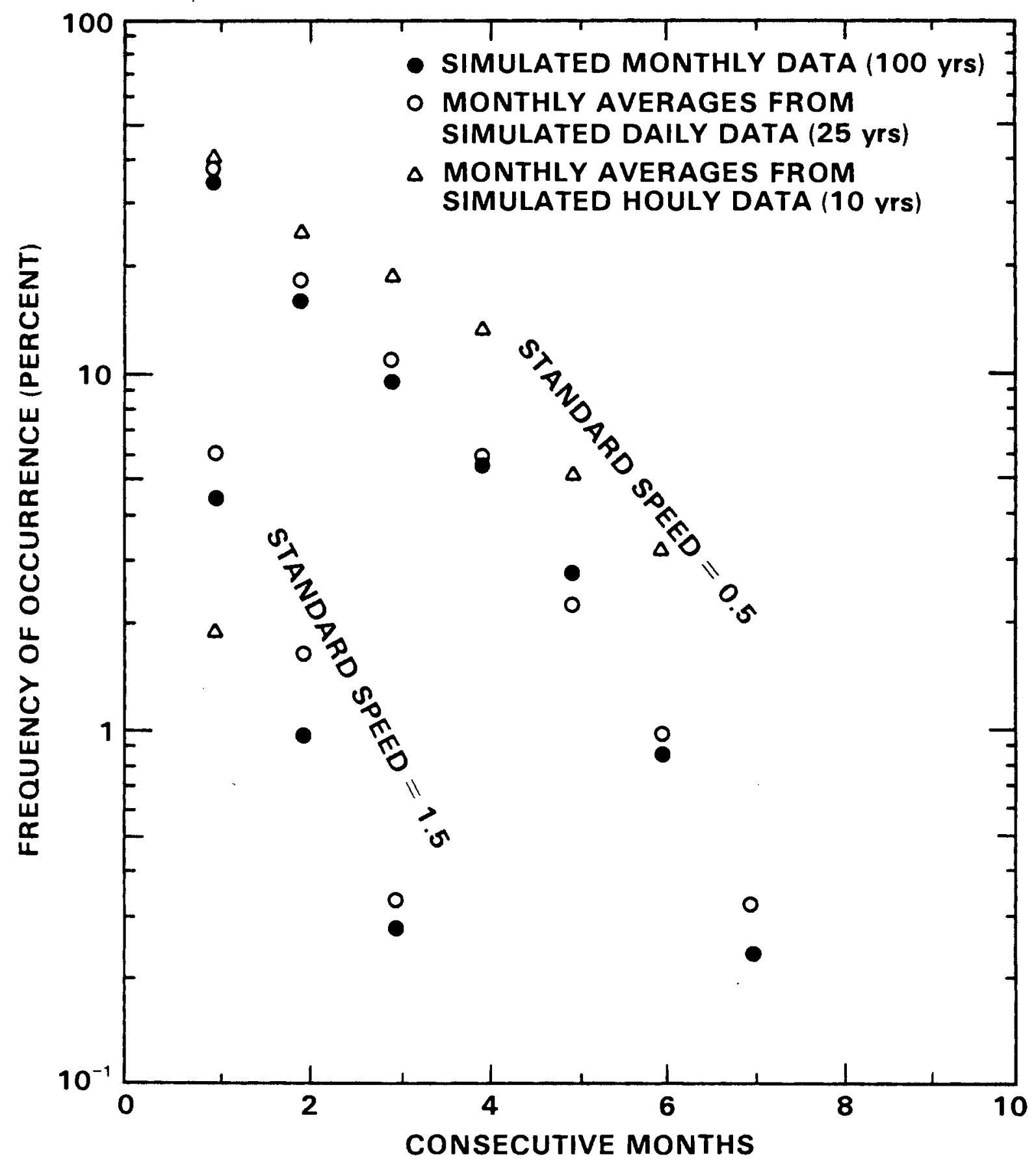

FIGURE 9. Persistence of Above Average Simulated Monthly Average Wind Speeds 


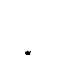




\section{CONCLUSIONS}

A time series model has been developed for the simulation of wind speeds. The model provides for the incorporation of systematic seasonal variation of the mean speed, its standard deviation, and the correlation coefficient. It also provides for incorporation of the systematic diurnal variation of the mean speed and the standard deviation.

As a demonstration of the model capabilities, a number of simulations have been made using model parameters derived from data collected at the Hanford Meteorology Station. The results of analyses of both sets of data, the simulated set and the real data, have been compared. In general the major features found in the analyses of the real data are identifiable in the corresponding analyses of the simulated data. The primary difference between the two data sets is in the frequency of high wind speeds. The frequencies of hourly and daily average wind speeds greater than 2 standard deviations above the mean are underestimated slightly by the model.

A second inconsistency appears to exist in the model. That inconsistency shows up when the simulated data are averaged. Too much variability is lost in the averaging process and the wind speed distributions approach normality too rapidly. The cause of the inconsistency has not been isolated, but potential contributing factors include: use of a distribution for the uncorrelated random variates that has too small coefficients of skewness and kurtosis, too rapid decay of the autocorrelation, and the partitioning of the variance in determination of the parameters for the standard deviation. This apparent inconsistency is not considered to be a serious problem, because it has been demonstrated that the model is capable of simulating both daily and monthly average wind speeds directly.

Since the simulations have been completed, the parameters for the diurnal variation of the standard deviation at the Hanford Meteorology Station have been evaluated. The phase of this additional variability is such that it would contribute significantly to the standard deviation at the time of the maximum mean wind speed. 
With these possible restrictions mentioned, the model appears to be a useful simulation tool that can be implemented without requiring excessive computational resources. Further tests with data from other locations are required to complete the model evaluation for economic simulation studies. Conceptually, however, the model is useful in its current state for detailed examination of the spatial correlation of winds at potential wind energy conversion sites, and for the evaluation of techniques for adjusting climatological statistics derived from limited observations. 


\section{REFERENCES}

Bendat, J. S. and A. G. Piers01. 1971. Random Data: Analysis and Measurement Procedures. Wiley, New York.

Bloomfield, P. 1976. Fourier Analysis of Time Series: An Introduction. Wiley, New York.

Brownlee, K. A. 1965. Statistical Theory and Methodology. 2nd ed., Wiley, New York.

Changery, M. J., W. T. Hodge and J. V. Ramsde 11. 1977. Index-Summarized Wind Data. BNWL-2220 WIND-11, Pacific Northwest Laboratory, Richland, Washington. Available from the National Climatic Center, Asheville, North Carolina.

Chou, K. C. and R. B. Corotis. 1981. "Simulation of Hourly Wind Speed and Array Wind Power." Solar Energy. 26:199-212.

Cliff, W. C., C. G. Justus and C. E. Elderkin. 1978. Simulation of the Hourly Wind Speeds for Randomly Dispersed Sites. PNL-2523, Pacific Northwest Laboratory, Richland, Washington.

Corotis, R. B., A. B. Sigl and M. P. Cohen. 1977. "Variance Analys is of Wind Characteristics for Energy Conversion." J.Appl. Meteor. 16:1149-1157.

Corotis, R. B., A. B. Sigl and J. Klein. 1978. "Probability Models of Wind Velocity Magnitude and Persistence." Solar Energy. 20:483-493.

Electric Power Research Institute. 1979. Technical Assessment Guide. EPRI PS-1201-SR, Electric Power Research Institute, Palo Alto, California.

JBF Scientific Corp. 1979. Wind Energy Systems Application to Regional Utilities. Vol. 1. JBF Scientific Corp., Wilmington, Massachusetts.

Justus, C. G., W. R. Hargraves, A. Mikhail and D. Graber. 1978. "Methods for Estimating Wind Speed Frequency Distributions." J. Appl. Meteor. 17:350-353.

Justus, C. G., K. Mani and A. S. Mikhail. 1979. "Interannual and Month-toMonth Variations of Wind Speed." J. Appl. Meteor. 18:913-920.

Kahn, E. 1978. Reliability of Wind Power for Dispersed Sites; A Preliminary Assessment. LBL-6889, Lawrence Berkeley Laboratory, Berkeley, California.

Papoulis, A. 1965. Probability, Random Variables and Stochastic Processes. McGraw-Hill, New York.

Pacific Northwest Laboratory. 1980-1981. Wind Energy Resource Atlas: Volumes 1-12. PNL-3195 WERA-1 through -12, Pacific Northwest Laboratory, Richland, Washington. 
Ramsde11, J. V., S. Houston and H. L. Wegley. 1980. "Measurement Strategies for Estimating Long-Term Average Wind Speeds." Solar Energy. 25:495-503.

Sigl, A. B., R. B. Corotis and D. J. Won. 1979. "Run Duration Analysis of Surface Wind Speeds for Wind Energy Application." J.Appl. Meteor. 18: 156-166.

Sorensen, B. 1978. "On the Fluctuating Power Generation of Large Wind Energy Converters, With and Without Storage Facilities." Solar Energy. 20:321-331.

Stone, W. A., D. E. Jenne and J. M. Thorp. 1972. Climatography of the Hanford Area. BNWL-1605, Pacific Northwest Laboratory, Richland, Washington. 
APPENDIX A

CHARACTERISTICS OF THE DISTRIBUTION OF THE CORRELATED SERIES 
APPENDIX A

\section{CHARACTERISTICS OF THE DISTRIBUTION OF THE CORRELATED SERIES}

The random variate used in the simulation of the hourly average wind speeds is derived from an underlying Rayleigh distribution. The distribution of the wind speeds is not Rayleigh. This appendix describes the distribution and its variation with increasing correlation coefficient.

The time series of random variates is a Markov chain. It is generated as follows

$$
x_{i}=\rho x_{i-1}+x^{\prime}
$$

where the $x_{i}$ are the correlated time series, $\rho$ is the correlation between consecutive elements of the series, and $x^{\prime}$ are uncorrelated random variates with a known distribution. If the distribution of the $x^{\prime}$ is Gaussian, then the distribution of the $x_{i}$ is also Gaussian and the correlation between elements $x_{i}$ and $x_{i-k}$ is given by

$$
\rho(k)=\exp (-\lambda k)
$$

where $k$ is the $\operatorname{lag}$ and $\lambda$ is a decay constant.

In our simulation the $x^{\prime}$ are not drawn from a Gaussian distribution, therefore we cannot assume that the $x_{j}$ have a Gaussian distribution. Similarly, it is not proper to assume that the $x_{j}$ have a Rayleigh distribution because the $x^{\prime}$ are drawn from a Rayleigh distribution. As a result we have examined the behavior of the moments of the $x_{i}$ distribution.

As a starting point, we note that if $x^{\prime}$ has zero mean, then $x_{i}$ will also have zero mean. In our simulation we have generated $x^{\prime}$ so that it has zero mean and unit variance. By taking the expectation of $x_{i}$ to the second, third and fourth powers, and recursively applying $(A-1)$ we obtain the following results 


$$
\begin{aligned}
& E\left[x_{i}^{2}\right]=\frac{1}{1-\rho^{2}} E\left[x^{\prime 2}\right] \\
& E\left[x_{i}^{3}\right]=\frac{1}{1-\rho^{3}} E\left[x^{\prime 3}\right] \\
& E\left[x_{i}^{4}\right]=\frac{6 \rho^{2}}{\left(1-\rho^{2}\right)\left(1-\rho^{4}\right)}\left\{E\left[x^{\prime 2}\right]\right\}^{2}+\frac{1}{1-\rho^{4}} E\left[x^{4}\right]
\end{aligned}
$$

which express the moments of the correlated distribution in terms of the moments of the underlying distribution and the correlation coefficient. From these relationships we draw the following conclusions: the variance, coefficient of skewness, and coefficient of kurtosis of our correlated time series should be

$$
\begin{aligned}
\operatorname{Var}\left[\mathrm{x}_{i}\right] & =\frac{1}{1-\rho^{2}} \\
\operatorname{SK}\left[\mathrm{x}_{i}\right] & =\frac{\left(1-\rho^{2}\right)^{3 / 2}}{\left(1-\rho^{3}\right)} \operatorname{Sk}\left[\mathrm{x}^{\prime}\right] \\
K\left[\mathrm{x}_{i}\right] & =\frac{6 \rho^{2}}{1+\rho^{2}}+\frac{1-\rho^{2}}{1+\rho^{2}} K\left[\mathrm{X}^{\prime}\right]
\end{aligned}
$$

respectively, where VAR[] is the variance and $S k[]$ and $K[]$ are coefficients of skewness and kurtosis. Approximate values for $S k\left[x^{\prime}\right]$ and $K\left[x^{\prime}\right]$ are 0.6322 and 3.2450 , respectively.

Figure A-1 shows comparisons of the standard deviations and coefficients of skewness and kurtosis of time series generated using (A- $T$ ) with values predicted using $(A-6)$ through $(A-8)$. The data shown in Figure $A-1$ were obtained in tests of the simulation procedure involving more than 9,000 elements. Three tests were run for each correlation coefficient. It is to be expected that the observed coefficients of skewness and kurtosis would show a larger scatter about 

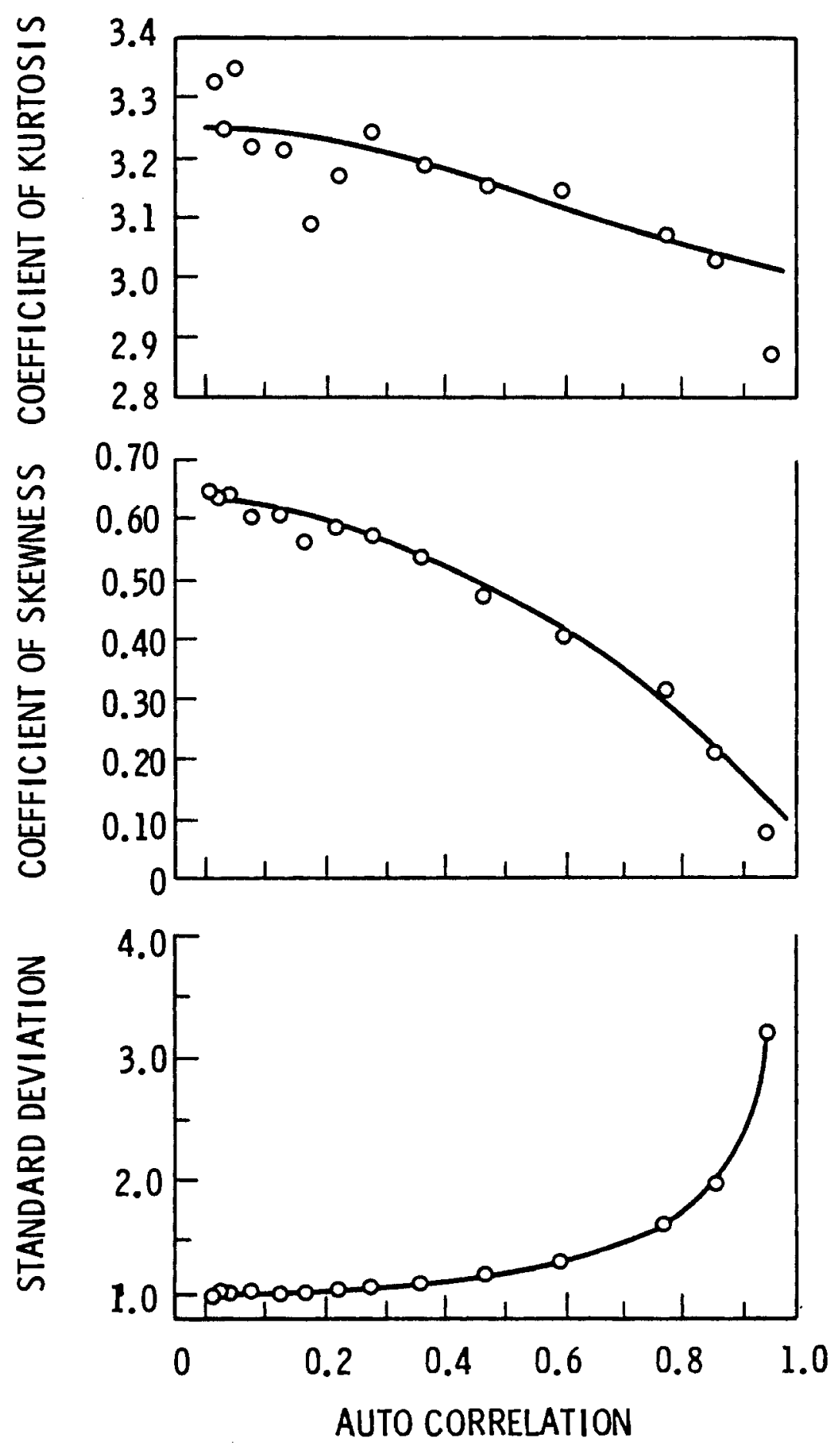

FIGURE A-1. Behavior of the Central Moments of the Distribution of Correlated Random Variates as a Function of the Correlation 
their predicted values than shown for the standard deviation because convergence to their predicted values is much slower.

Relationships (A-3) through (A-8) apply for $i$ sufficiently large that $\rho^{\text {ni }}$, $n=2,3$ or 4 , can be assumed to be equal to zero. Thus, if we want the distribution of $x_{i}$ to be constant throughout the simulation, we must discard the first few elements of the chain prior to starting the simulation. In practice, we have initialized the simulation by discarding the first 65 elements of the chain.

Figures $A-2$ and $A-3$ show the behavior of the correlation coefficient for our chain. Figure $A-2$ demonstrates that the correlation observed between $x_{i}$ and $x_{i-1}$ is the same as that correlation used in $(A-1)$. The effect on correlation of increasing the separation between elements is shown in Figure A-3. The correlation used in $(A-1)$ for each test was $e^{-\lambda}$. From this figure we conclude that changing the distribution of $x^{\prime}$ from $N(0,1)$ to $R(0,1)$ has not negated $(A-2)$. 


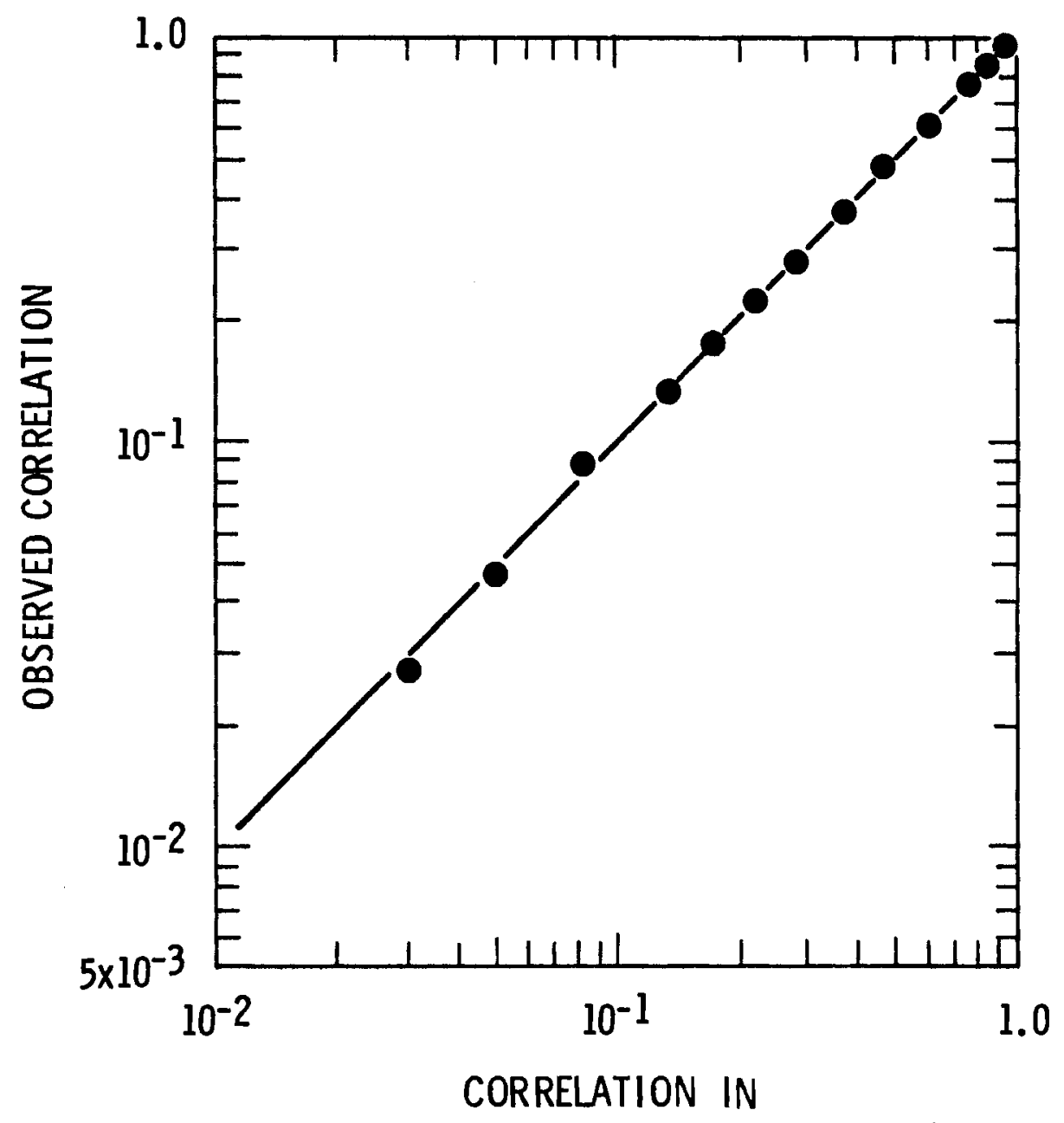

FIGURE A-2. Comparison of Intended Correlations with Conditions Observed in the Simulated Data 


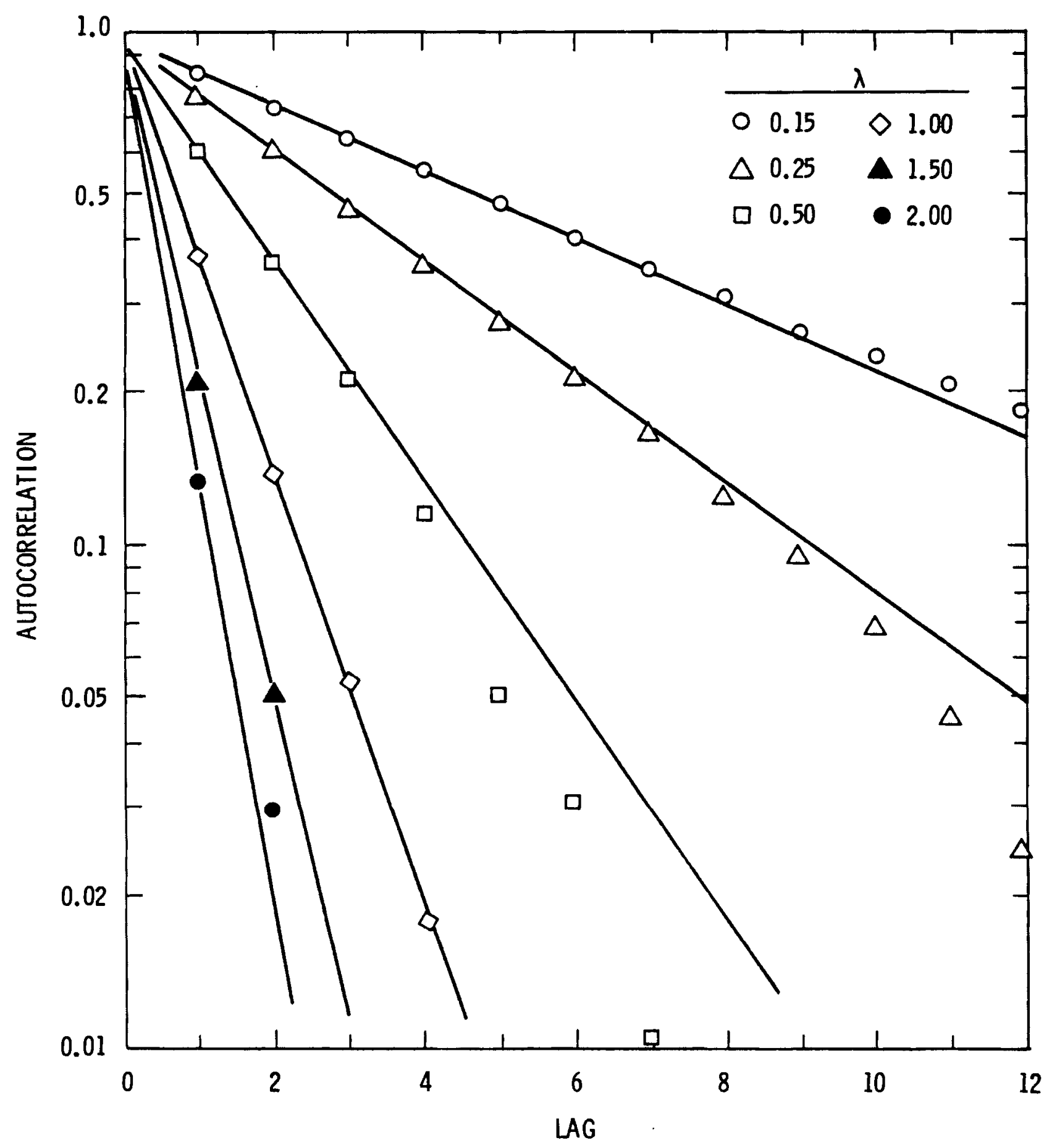

FIGURE A-3. Decay of Autocorreiations in the Simulated Time-Series 
APPENDIX B

HOURLY WIND SPEED SIMULATION PROGRAM 


\section{APPENDIX B}

\section{HOURLY WIND SPEED SIMULATION PROGRAM}

A computer program has been written to simulate hourly wind speeds using the model developed in the body of the report, combine the hourly data into daily and monthly averages, and analyze each of the data sets. This appendix describes the program.

The program is divided into four basic sections: initialization, model parameter input, simulation and analysis. The initialization section sets variable types and array dimensions. It consists of the first 11 program lines. Line numbers are indicated to the left of the code in the listing at the end of the appendix. Array names and uses are listed in Table B-1, and variable names and uses are listed in Table B-2.

Input of model parameters and parameters for control of the simulation takes place in the next section; lines 13 through 46. At the end of the parameter input section the value of each of the parameters is printed to provide a record of the input associated with the model output. Numbers at the extreme left of the program listing indicate do-loop nesting. The name and use of each of the subroutines used in the program are listed in Table B-3.

Subroutine CARLOH, called in line 52, contains the simulation section of the program. It starts with pseudo-random $\mathrm{N}(0,1)$ deviates, forms Rayleigh deviates, then transforms the Rayleigh deviates to $R(0,1)$. These deviates are combined with model parameters to give the hourly wind speed time series. The hourly speeds are written to disk a year at a time for temporary storage. CARLOH also computes daily average wind speeds from the hourly values. The daily averages are stored in an array in computer memory.

The development of the wind speed time series in CARLOH is a step-by-step process. In lines 179 through 185 the seasonal variations of the mean and standard deviation are computed. 
TABLE B-1. Arrays Used in the Wind Speed Simulation Program

NAME

USE

ACOR Autocorrelations

ACV Autocovariances

AVE Average wind speeds for day of the year

CKURT Coefficients of kurtosis of daily average speeds for day of the year

HEADER Title or description of simulation

IYR Sequential number of year simulated

LAMDA Model parameter for autocorrelation of simulated time series

LIM Run length limits for persistence analysis

NRUNS Accumulates runs for persistence analysis

SD Standard deviations of daily average speeds for day of the year

SKEW Coefficients of skewness of daily average speeds for day of the year

SLIM Speed limits for persistence anlaysis

SWS Simulated daily average wind speeds (day of year, year)

VAR Variances of daily average speeds for day of year

W Simulated daily average speeds (1 dimensional array equivalent to SWS)

WR Departures of daily average speeds from average for day of the year ( 1 dimensional array equivalent to WSR)

WRM Departures of monthly average speeds from average for the month

WS Simulated monthly average speeds (month, year)

WSR Departures of daily average speeds from average for day of the year (day of year, year)

Z Work space for temporary storage of the simulated hourly average wind speeds

ZZ Work space for temporary storage of hourly wind speeds 
TABLE B-2. Variable Names Used in the Ma in Program

NAME

A0

A1

A2

B

BO

BT

BPHI

DEL

GAMA

HAVE

HKURT

HSD

HSKEW

HVAR

IDATE

IPASS

ITIME

M

MM

NHS

NYRS

PHIO

USE

Amplitude of the seasonal variation of the mean speed $\left(A_{1}\right.$ in Eq. 2) Mean amplitude of the diurnal variation of the mean speed $\left(A_{2}\right.$ in Eq. 2a)

Amplitude of the seasonal variation of the amplitude of the diurnal variation of the mean speed $\left(\mathrm{A}_{3}\right.$ in Eq. $2 \mathrm{a}$ )

Standard deviation of the wind speed when no variability is treated ( $\mathrm{B}_{0}$ in Eq. 3)

Mean standard deviation of the wind speed ( $B_{0}$ in Eq. 3)

Amplitude of the seasonal variation of the standard deviation of the wind speed ( $\mathrm{B}_{1}$ in Eq. 3 )

Phase angle for the seasonal variation of the standard deviation ( $\theta_{1}$ in Eq. 3)

Wind speed band width for persistence analysis

Phase angle for the seasonal variation of the autocorrelation decay constant ( $\gamma$ in Eq. 6)

Overall average of the simulated hourly wind data

Overall coefficient of kurtosis of the simulated hourly wind data

Overall standard deviation of the simulated hourly wind data

Overall coefficient of skewness of the simulated hourly wind data

Overall variance of the simulated hourly wind data

Date of the simulation

Switch used to select one of several possible simulation models

Time of day of the simulation

Number of days to be simulated

Number of months to be simulated

Number of hours per record for disk storage of hourly wind data

Number of years to be simulated

Phase angle for the seasonal variation of the mean speed $\left(\phi_{0}\right.$ in Eq. 2) 
TABLE B-2 (contd)

NAME

PHI1

PHI2

PHI3

PHI4

VBAR

XLAMO

XLAM1

USE

Phase angle for the seasonal variation of the amplitude of the diurnal variation of the mean speed ( $\phi_{1}$ in Eq. 2a)

Mean phase angle for the diurnal variation of the mean speed ( $\phi_{2}$ in Eq. 2a)

Amplitude of the seasonal variation of the phase angle for the diurnal variation of the mean speed ( $\phi_{3}$ in Eq. 2a)

Phase angle of the seasonal variation of the phase angle of the diurnal variation of the mean speed ( $\phi_{4}$ in Eq. 2a) Long-term average wind speed ( $A_{0}$ in Eq. 2) Mean decay constant for the autocorrelation ( $\lambda_{0}$ in Eq. 6) Amplitude of the seasonal variation of the decay constant for the autocorrelation $\left(\lambda_{1}\right.$ in Eq. 6) 
TABLE B-3. Subroutines Used in the Wind Speed Simulation Program

NAME USE

ADATE UNIVAC System routine used to supply the date and time of the simulation

CARLOH Monte Carlo simulation of hourly wind speeds and computation of daily average speeds

CMTS1 Computes central moments of data in a 1-dimensional array

CMTS2 Computes the central moments of data in columns of a 2-dimensional array

FREQ Compiles frequency and cumulative frequency distributions of data in a 1-dimensional array

FREQA Compiles frequency and cumulative frequency distributions of data in a 1-dimensional array using standardized bin widths

FREQM Same as FREQ except for smaller bin widths, used for monthly averages.

FTAUTO International Mathematical and Statistical Libraries, Inc. (IMSL) subroutine to compute autocovariances and autocorrelations

GGNML IMSL subroutine to generate pseudo-random, normal deviates with zero mean and unit variance

GROUP Combines daily average wind speeds into monthly averages

HCMTS1 Same as CMTS1, except reads data from disk, used for hourly speeds HFREQ Same as FREQ except reads data from disk, used for hourly speeds HFREQA Same as FREQA except reads data from disk, used for hourly speeds HRUNS Same as RUNS except reads data from disk, used for hourly speeds RUNS Persistence anlaysis of data in 1-dimensional arrays WAUTO Output autocovariances and autocorrelations WDATIX Output moments of the daily average wind speed sitributions by day of the year

WDATIY Output monthly average wind speed statistics WRUNS Output results of persistence analysis 
Seasonal variations of the amplitude and phase angles of the diurnal variation are also computed in this section.

The section of CARLOH between 1 ines 186 and 193 generates the first 65 terms in the time series of $R(0,1)$ deviates. The last of these values is used as the initial value in the simulation. The remaining values are discarded; their purpose is to allow the moments of the distribution of correlated deviates to stabilize. The remainder of the simulated values are generated between 1 ines 195 through 204.

The section of the code between lines 205 and 218 ensures that the series of correlated deviates has zero mean and unit variance. This section could be eliminated if each simulated value were scaled by division by the theoretical standard deviation for the correlated time series derived in Appendix A.

The conversion of the deviate time series to wind speeds occurs in lines 219 through 226. If diurnal variations of the mean speed and standard deviation are to incoporated in the model, their respective contributions must be computed and included in this section. This can easily be done by expanding the left side of the equation in line 221.

Lines 222 and 224 compute daily average wind speeds. The remainder of the program, lines 57 through 166, consists of the analysis section. Hourly wind data are analyzed first, lines 57 through 82 . The analyses performed include: computation of the first 4 central moments of the wind speed distribution, compilation of frequency and cumulative frequency distributions, and compilation of persistence statistics for wind speeds above and below average. To facilitate comparisons between analyses of data from different time periods at a single site or different sites, frequency and persistence statistics are compiled in standardized wind speed ranges.

Daily average speeds are analyzed following the analysis of the hourly speeds. The pattern of analysis of the daily averages initially follows that of the hourly values. After the persistence analysis is completed, the daily averages are determined. The initial correlation computation includes the effects of seasonal variation of both the mean and standard deviation. Monthly averages are compiled from the daily averages, then the seasonal 
variation of the mean is removed and the autocorrelation of the daily averages is recomputed. Finally, the seasonal variation of the standard deviation is removed, and the autocorrelation is computed again. This pattern is repeated for analysis of the monthly averages.

The simulation program, as it now exists, requires 44,500 words of user memory in a UNIVAC 1100/44. A large part of the memory requirement comes from the analysis portion of the program. A significant reduction in memory requirements could be achieved by optimization of the code and elimination of the analysis routines. Program execution requires about 12 seconds of CPU time per year of simulated data. Again, a large portion of the time is spent in the analysis of the data rather than the simulation. The complexity of the simulation model has little apparent effect on the time required. 


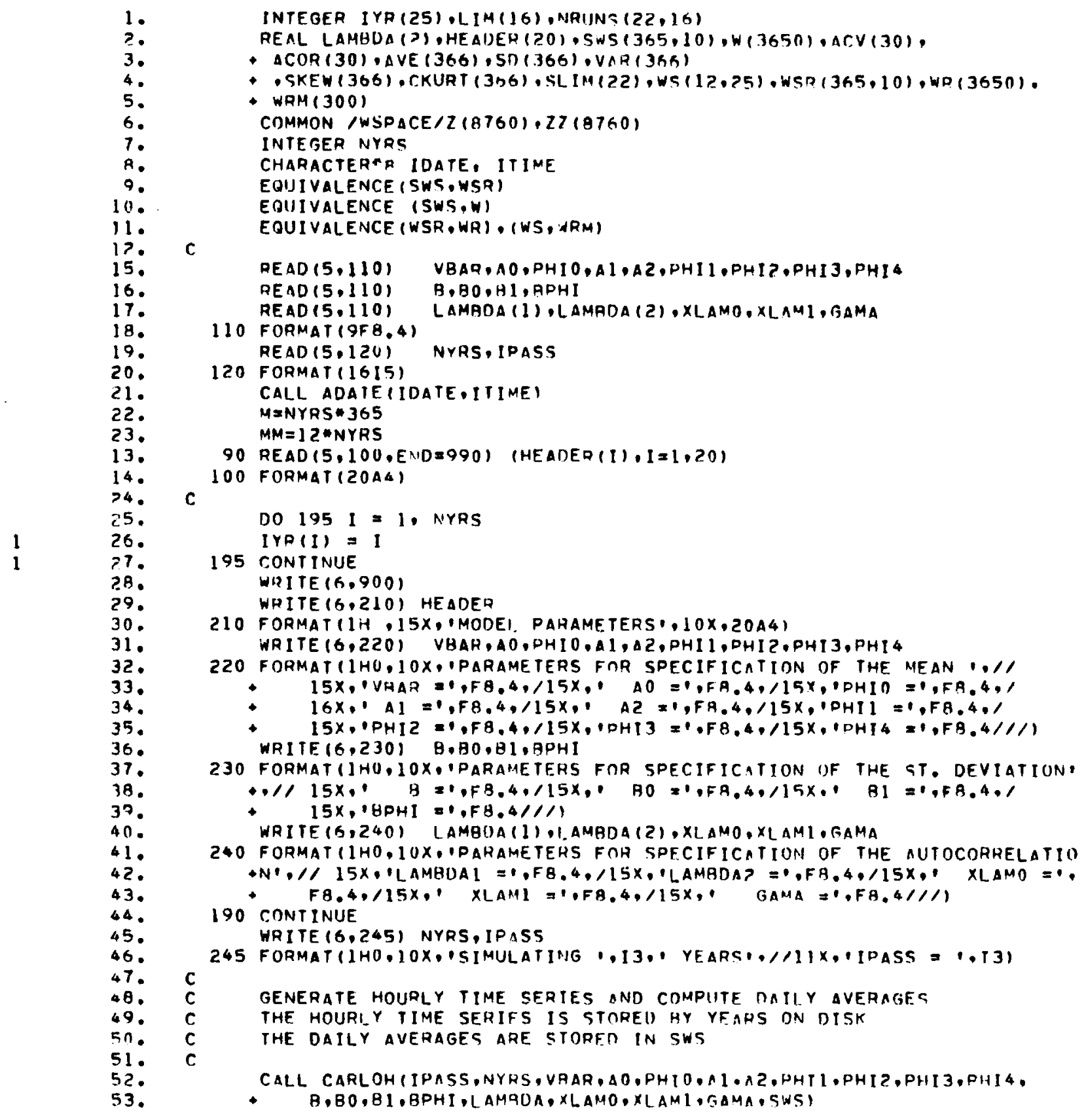




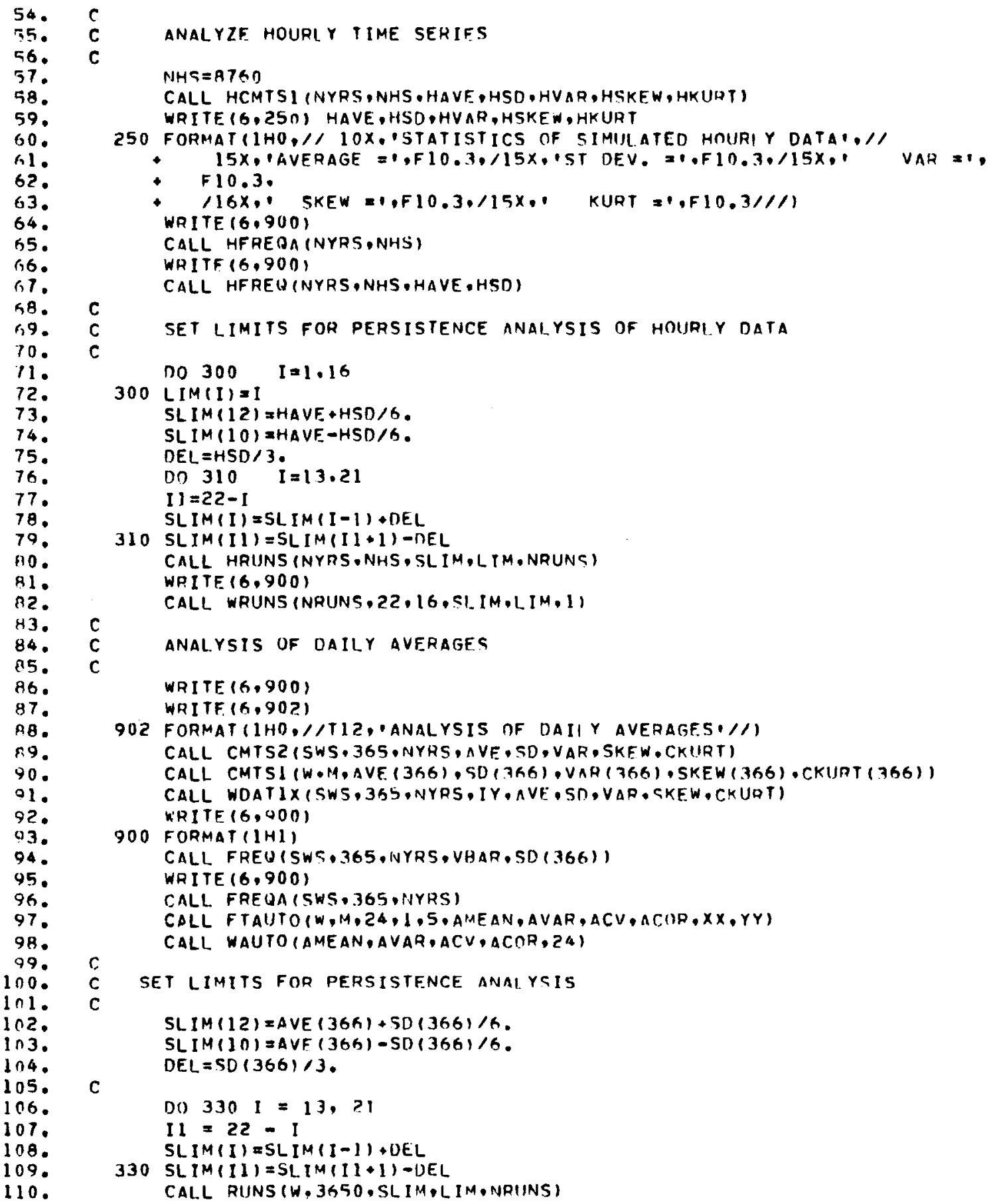




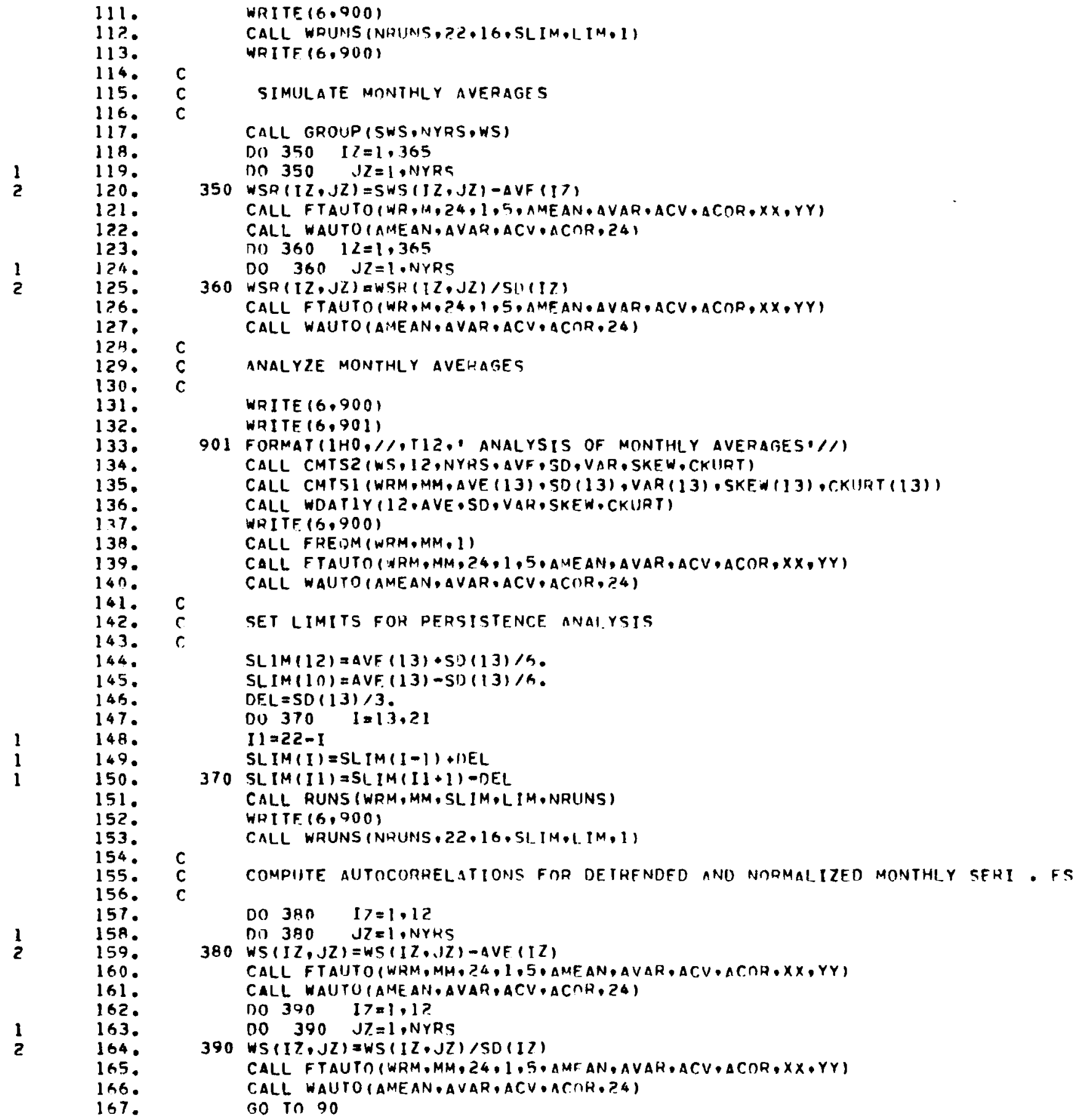


168. 169.
990 CONTINUE

END
170.

171.

172.

173.

174.

175.

176.

177.

178.

179.

180.

181.

182.

183.

184.

145 .

186.

187.

189 .

1 ค9.

190.

191.

192.

193.

194.

195.

196.

197.

198.

199.

2ก4.

205.

$2 n 6$.

$2 \pi ;$.

208.

209.

210.

211.

212.

213.

200.

214.

201.

202.

203.

215.

216 .

SUBHOUTINE CARLOHIIPASS,NYRS, VBAR,AO,PHTO,AI OA?,PHI I,PHIZ,PHT3, - PH[4,B,BO,BI,BPHI,LAMBDA, XLAMO,XLAM],GAMA,WSDI

REAL X(366),WSD(365,NYRS), R(365), RY (365) ,LAMADA (2), HA (24) , HA (365), $+U U(365)$,WS $(24,365)$, WS $1(8760)$, COEF (365), DSD (365), HC (365)

EQUIVALENCE (WS,WSI)

DOUBLE PRECISION DSEED

EXTERNAL MSEC

$M=M S E C()$

$x(300)=0.0$

D) $5 \quad I=1.365$

ANG $=0.0172 *(1-0.5)$

$\mathrm{UU}(I)=V B A H+A \Pi \div I N(A N G+P H I 0)$

$H B(I)=A I+A Z * S I N(A N(;+P H I I)$

$H C(I)=P H[2+P H I 3 * S I N(A N G+P H I 4)$

IF (IPASS.EA. I) DSO (I) =8

IF (IPASS.GE.2) DSO I ) $=H 0+B I * S I N(A N G+B P H I)$

IF (IPASS.GE.3) $\operatorname{COEF}(I)=E X P(X L A M O+X L A M I * S I N(A N G+G A M A)$ )

5 CONTINUE

DSEED $2 M$

CALL GGNML (DSEED,65.R)

CALL GGNML (DSEED,65,RY)

IF (IPASS.LE.?) RCOEF =EXP (LAMBDA (IPASS))

DO $10 \quad I=301 \cdot 36 \mathrm{~A}$

IF (IPASS. EQ. T) RCOEF $=\operatorname{COEF}(1-1)$

$X(I)=X(I-1)+R C \cap E F+(S A R T(R,(1-300) * \$ ?+R Y(T-30 n) * 2)-1.25331) / .65514$

10 CONTINIJE

DO $150 \quad N=1$, NYRS

no $100 \quad I=1.24$

$11=(1-1) * 365$

CALL GGNML (DSEED, $365, R)$

$X(J)=X(J-1) * R C O E F+(S \cap R T(R(J-1) * 2+R Y(J-1) \notin * 2)-1.25331) / .65514$

$W S 1(I 1+J-1)=x(J)$

100 CONTINUE

SUM $=0$.

$\operatorname{SUM} I=0.0$

SUMZ $=0.0$

DO $110 \quad J=1.365$

DO $110 \quad I=1.24$

$S U M=S U M+W S(1, J)$

SUMZ = SUM? WS $(I, J): 2$

CALL GGNML (DSEED, 365,RY)

110 CONTINUE

$x(1)=x(366)$

$00100 \quad J=2.366$

IF (IPASS, ED. 3) RCOEF $=\operatorname{COEF}(J-1)$

$A V E=S U M / B 76 \cap$.

SD $=$ SOHT (SUMR/A759. - SUM* $* 2 / 18760 * 8759.1$ ) 


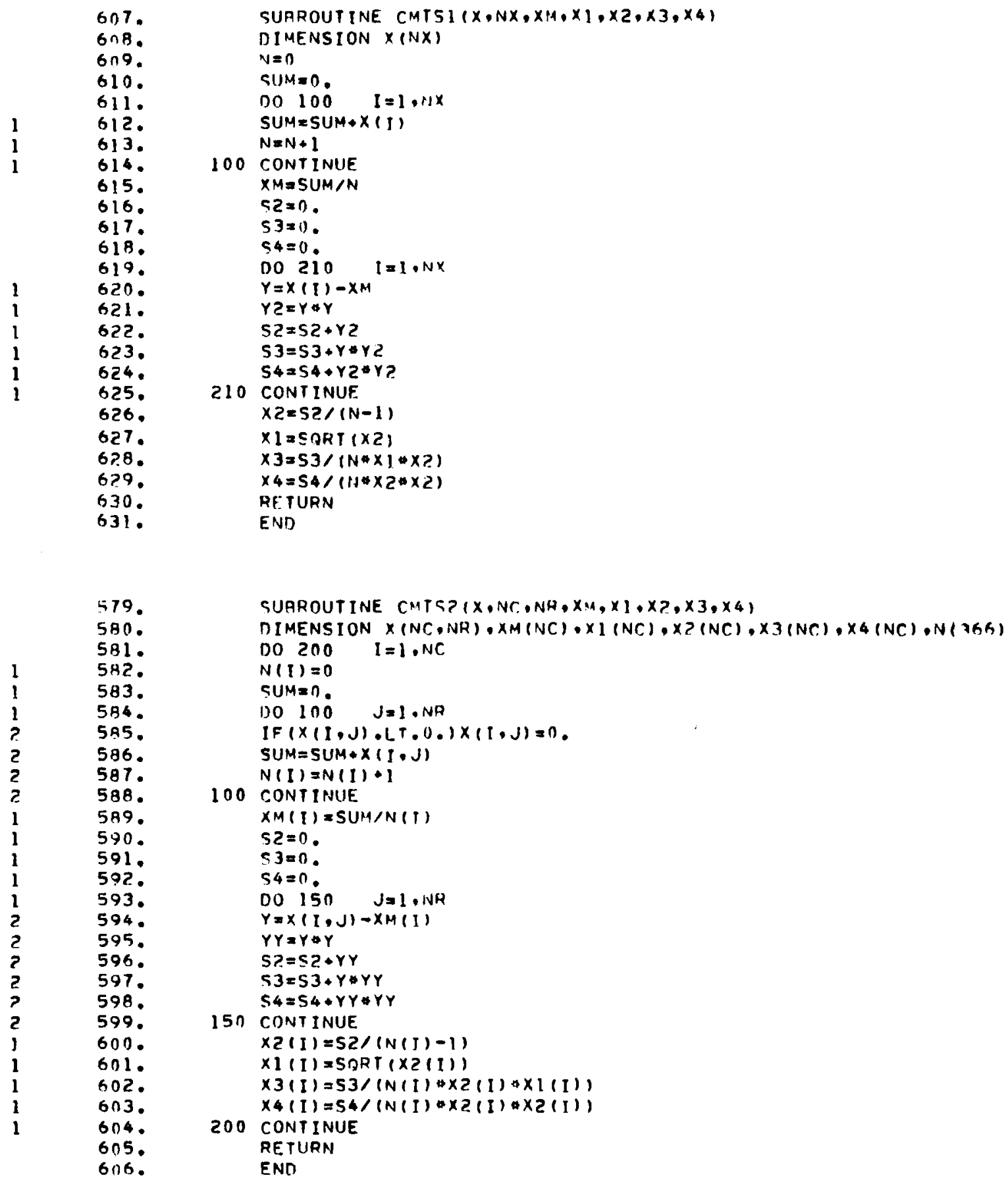




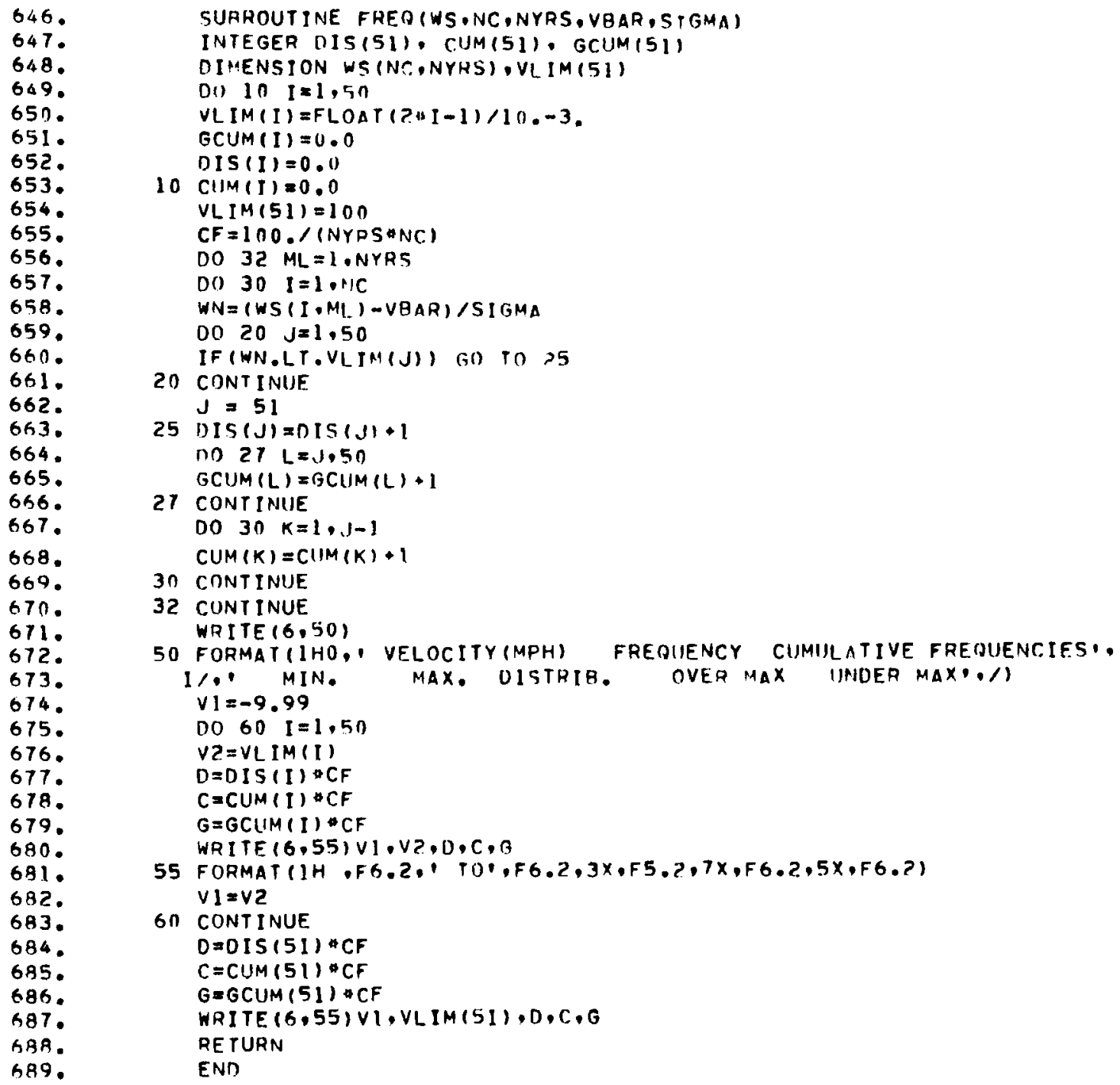




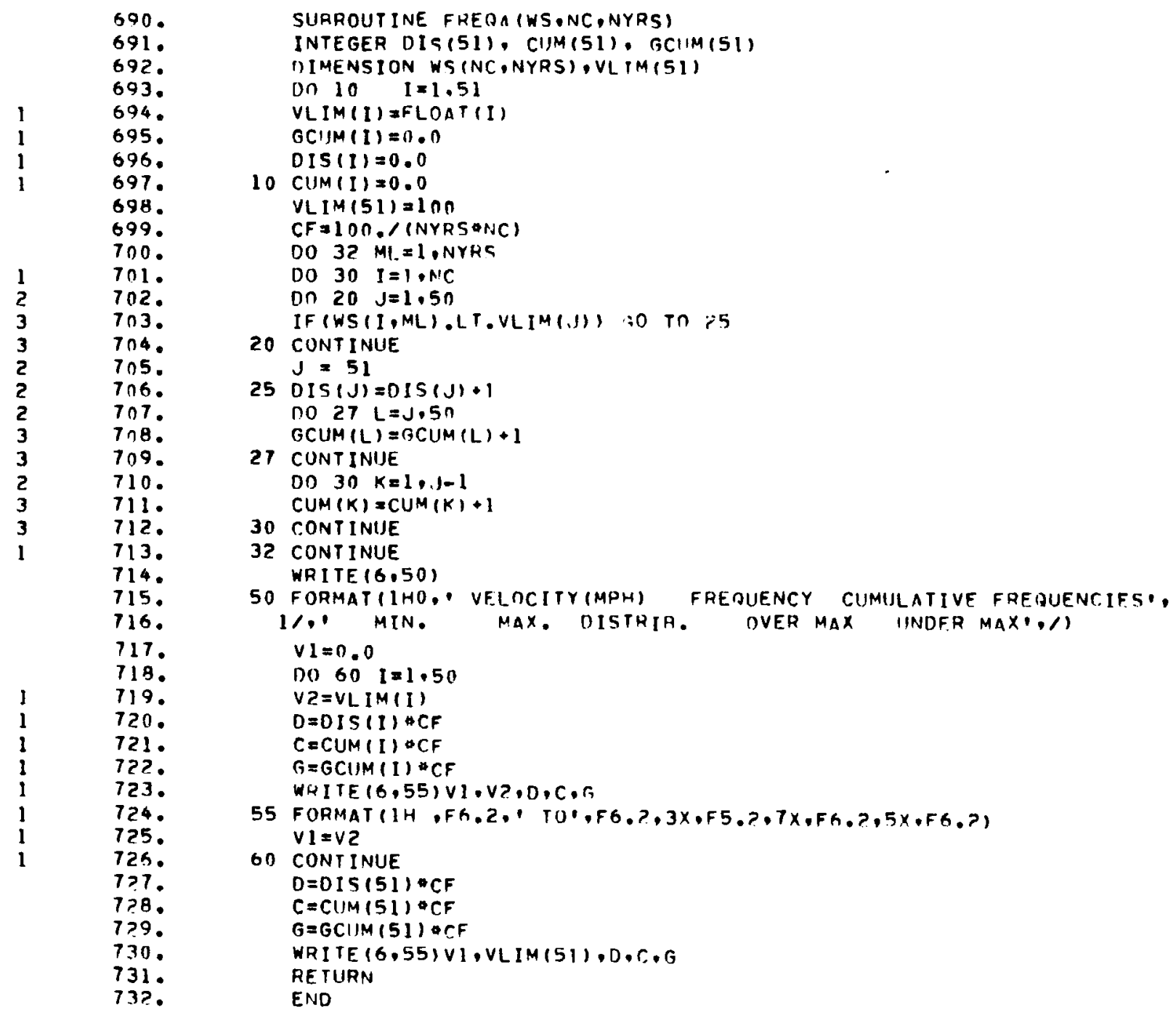




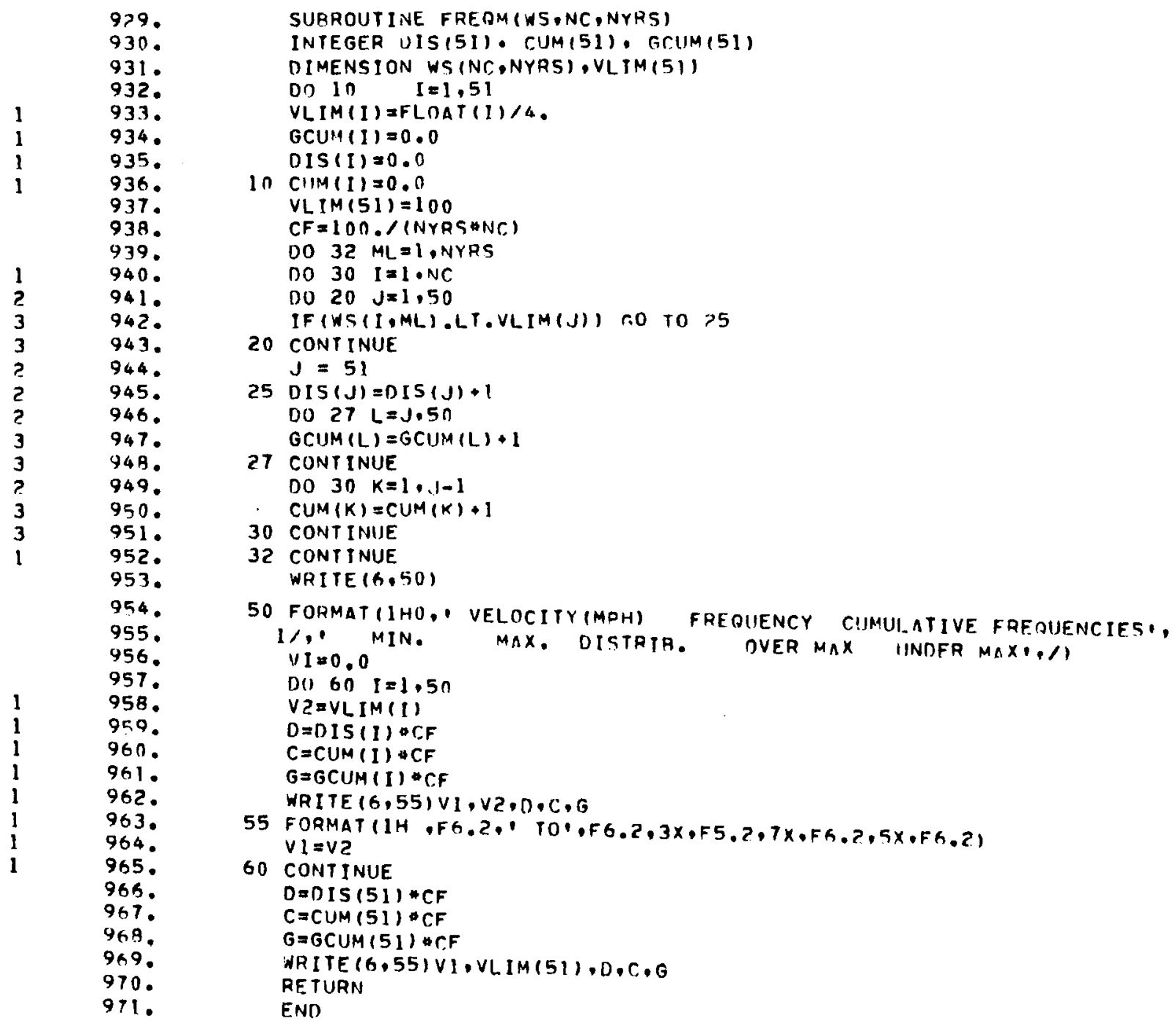

END FTN 3913 IBANK 22996 DAANK 17520 COMMON 


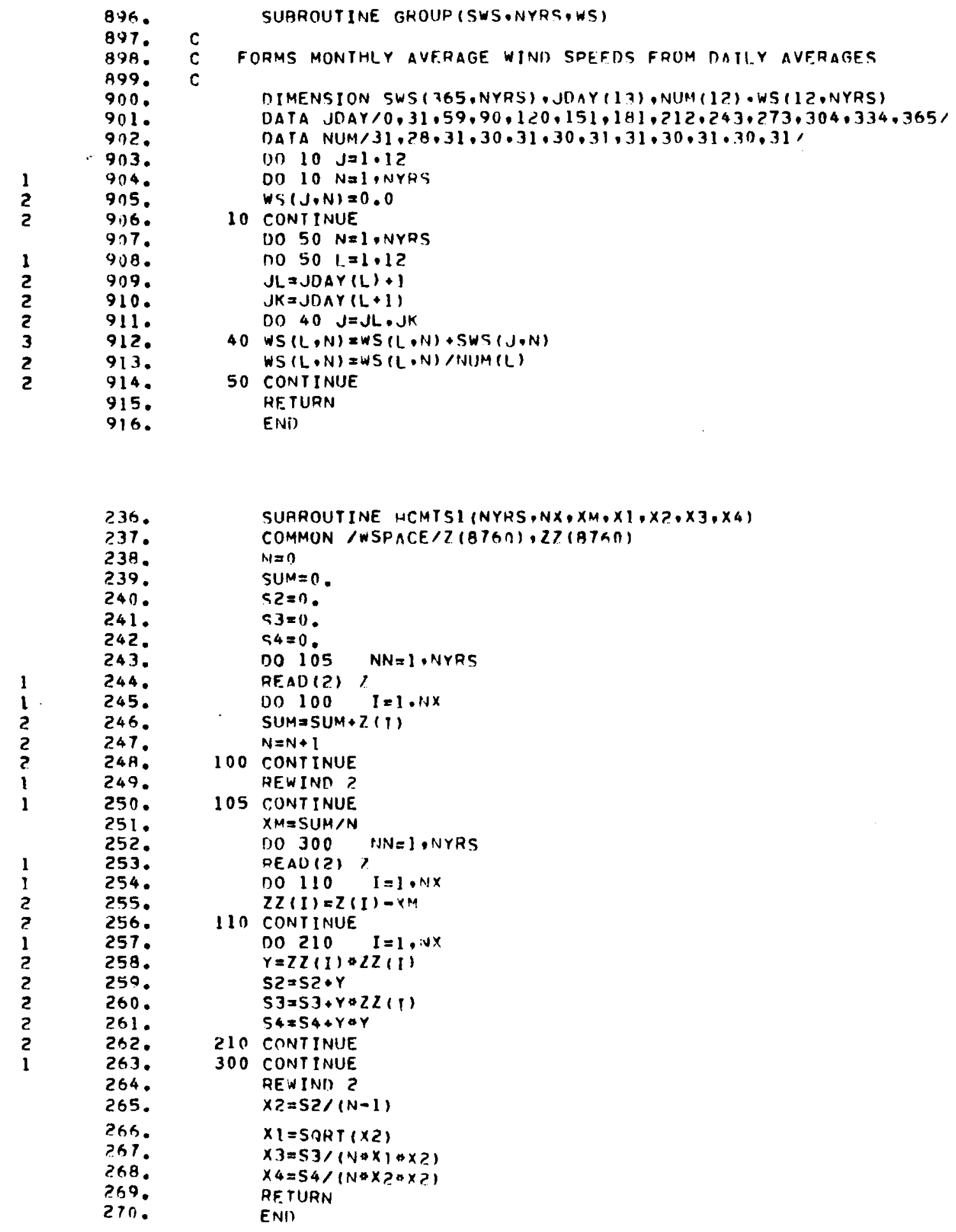




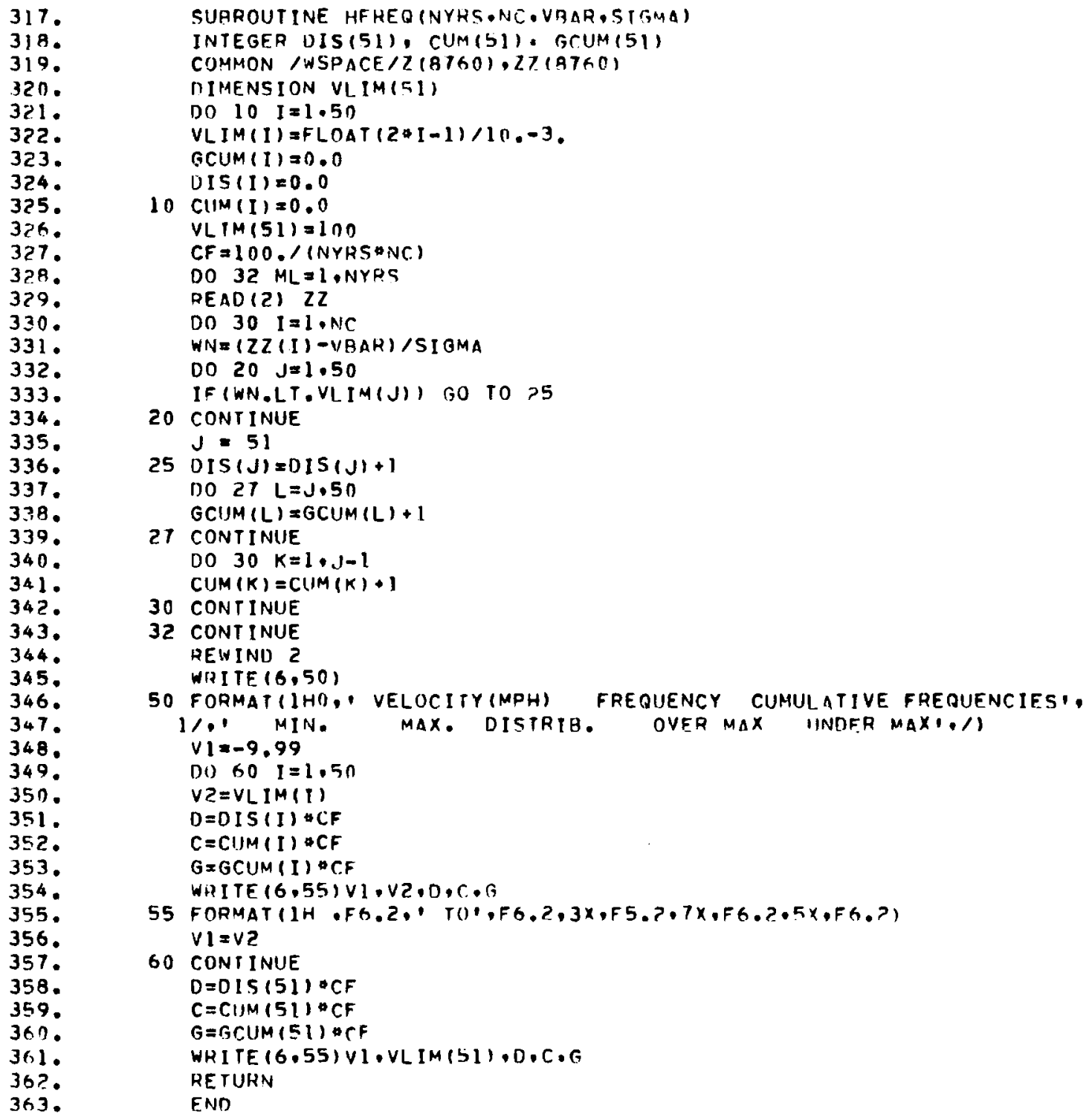


272

SUBROUTINE HFREDA (NYRS, NC)

INTEGER DIS(51), CUMIS1), GCUM(51)

COMMON /WSPACE/L(B760):ZZ(B760)

D) IMENSION VLIM(EI)

UO $10 \quad I=1.51$

$V L I M(I)=F L O A T(I)$

$\operatorname{GCUM}(I)=0.0$

$0 I S(I)=0.0$

In $\operatorname{CUM}(I)=0.0$

VLIM(5) $I M I n \cap$

$C F=100.1$ (NYRS BNC)

DO $32 \mathrm{ML}=1$. NYKS

READ (?) 27.

DO $3 n I=1 \cdot N C$

$0020 \quad J=1.50$

IF(ZZ(I).LT.VLIM(J)) GO TO 25

20 CONTINUE

$J=51$

25 DIS $(J)=0 \operatorname{ts}(7)+1$

DU $27 L=J .50$

$\operatorname{GCUM}(L)=G \operatorname{CUM}(L)+1$

27 CONTINUE

DO $30 \mathrm{~K}=1 \cdot J-1$

$\operatorname{CUM}(K)=\operatorname{CIJM}(K)+1$

30 CONTINUE

32 CONT INUE

REWIND ?

WRITE $(6.50)$

50 FORMATIIHO.' VELOCITY(MPH) FREOUFNCY CUMULATIVE FREDUENCIES', $1 \%$ MIN. MAX. DISTRIB. OVER MAX IJNDER MAXI,/I

$V 1=0.0$

D) $601=1.50$

$V Z=V L I M(I)$

$D=D I S(I) \bullet C F$

$C=C U M(I) * C F$

$G=G C U M(I) * C F$

WR ITE $(6,55) \vee 1, V 2,0, C, G$

55 FORMAT(1H OFG.2, TOI.F6.2.3X.F5.?.7X,FG.?.5X.FG.2)

$\vee l=\vee 2$

60 CONTINUE

$\mathrm{D}=\mathrm{DIS}(51)^{\circ} \mathrm{CF}$

$C=C U M(51) \circ C F$

$G=G C U M(51) \circ C F$

WRITE $(6,55)$ VI, VLIM $(51), 0, C, G$

RE TURN

ENO 
364.

365.

366 .

367 .

368 .

369.

370.

371 .

372 .

373.

374.

375.

376.

377.

378 .

379.

380 .

3 ค1.

382.

343.

384 .

385 .

336 .

$3 R 7$.

उВค.

389.

390.

391.

392.

393.

394.

345.

396.

397.

398.

399.

400.

$4 n 1$.

$4 n 2$.

403.

404 .

$4 \cap 5$.

$4 \cap 6$.

407 .

$4 \cap A$.

409.

410.

411.

412 .

413.

414.

415.

416.

417.

418 .

419.

SURROUT INE HAUNS (NYHS,NT DSLIM,I. IM,NRUNS)

COMMON /WSPACE/Z (87RO), ZZ (67\%O)

DIMENSION SI IM(21),LIM(16), IC (22),NRUNS(2?,16)

$J 2=0$

$001 \quad 1=1 \cdot 22$

IC (I) $=0$

DO $1 \quad J=1.16$

1 NRUNS $(I, J)=0$

DO $600 \quad N Y=1$, NYRS

REAO (2) $?$

DETEHMINF DEPARTURE

DO $600 \quad I T=1, N T$

DO $50 \quad 111=12,21$

IF (ZIIT).GE.SLIM(IU)) GO TO 10

$I L=\zeta 2-I U$

IF ( $2(I T) . L F . S L I M(I L))$ GO TO 20

IF (ZIIT).LT.SLIM(IZ).AND.Z(IT).GT.SLIM(IO)) G0 TO 60 GO TO 100

10 CONTINUE

I I $\approx$ I U

GO TO 30

20 CONTINUE

$I I=I L$

30 CONTINUE

IC (II $)=I C(I I)+1$

50 CONTINUE

GO TO 100

60 CONTINUE

$I I=11$

$I C(I I)=I C(I I)+]$

100 CONT INUE

c.

$J 1=11$

DETERMINE DURATION OF DEPARTUHE

IF $(J 2 . F(0.0)$ GO IO 500

IF $(\mathrm{J} 2-11) 200,300,400$

200 IF (J1.LE.JZ) GO TO 500

IF (JI.LE. II) J3=J1-1

IF(J1.GT.12) J3=In

DO $230 \quad I=J 2 \cdot J 3$

$J=I C(1)$

DO 220

$L L=17-L$

IF (J.GE.LIM(16)) SO TO 210

IF (LIM(LL).GT.J) GO TO 220

210 CONTINUE

NRUNS $(I \cdot L L)=$ NRUNS $(I \cdot L L)+1$

IC $(I)=0$

GO TO 230

Z20 CONT INUE

230 CONTINUE

GO TO 500

300 CONTINUE

IF (J1.EQ.11) GO TO 500

$J=I C(11)$

Do $320 \quad L=1.16$

$L L=17-L$ 


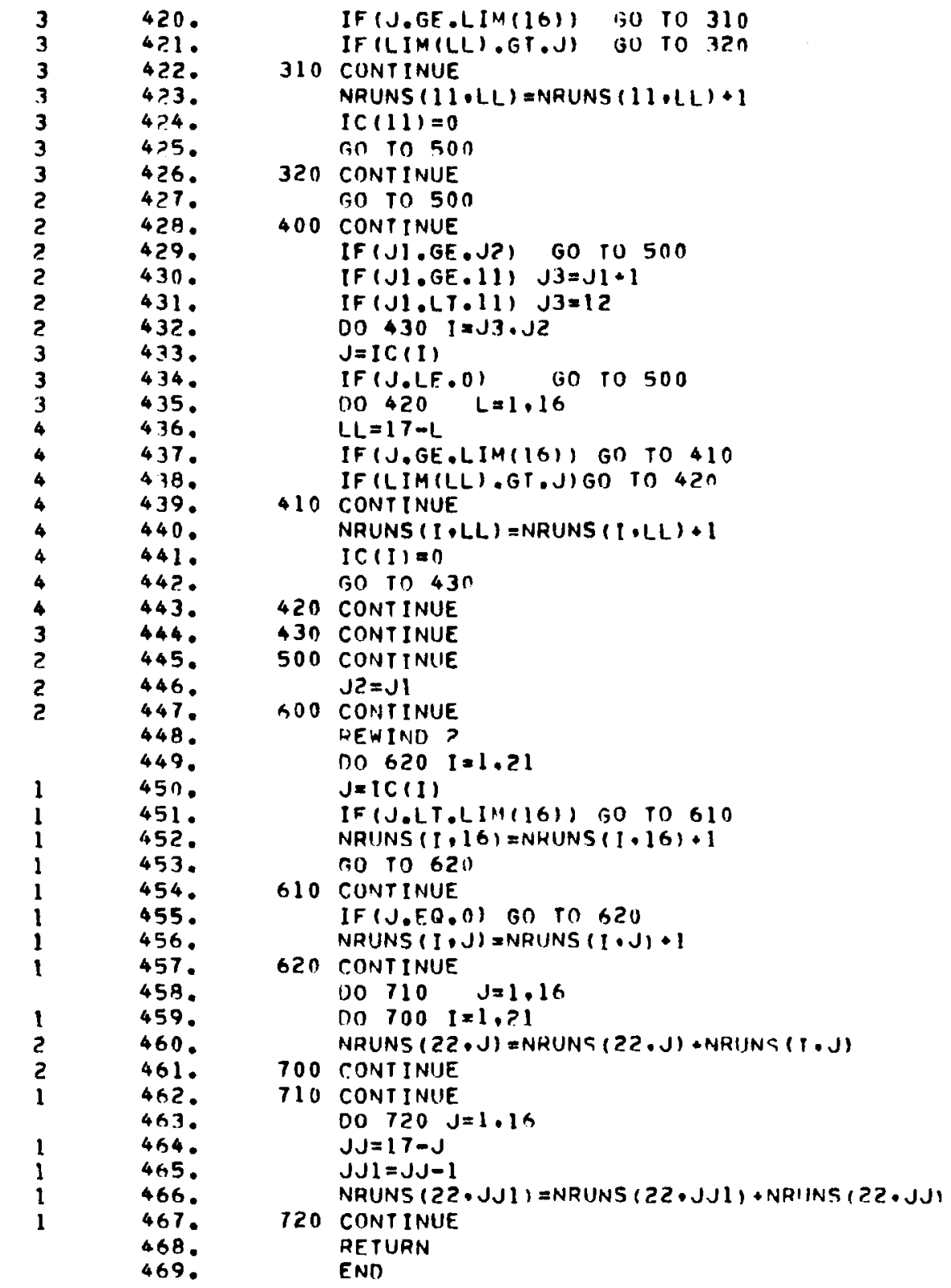




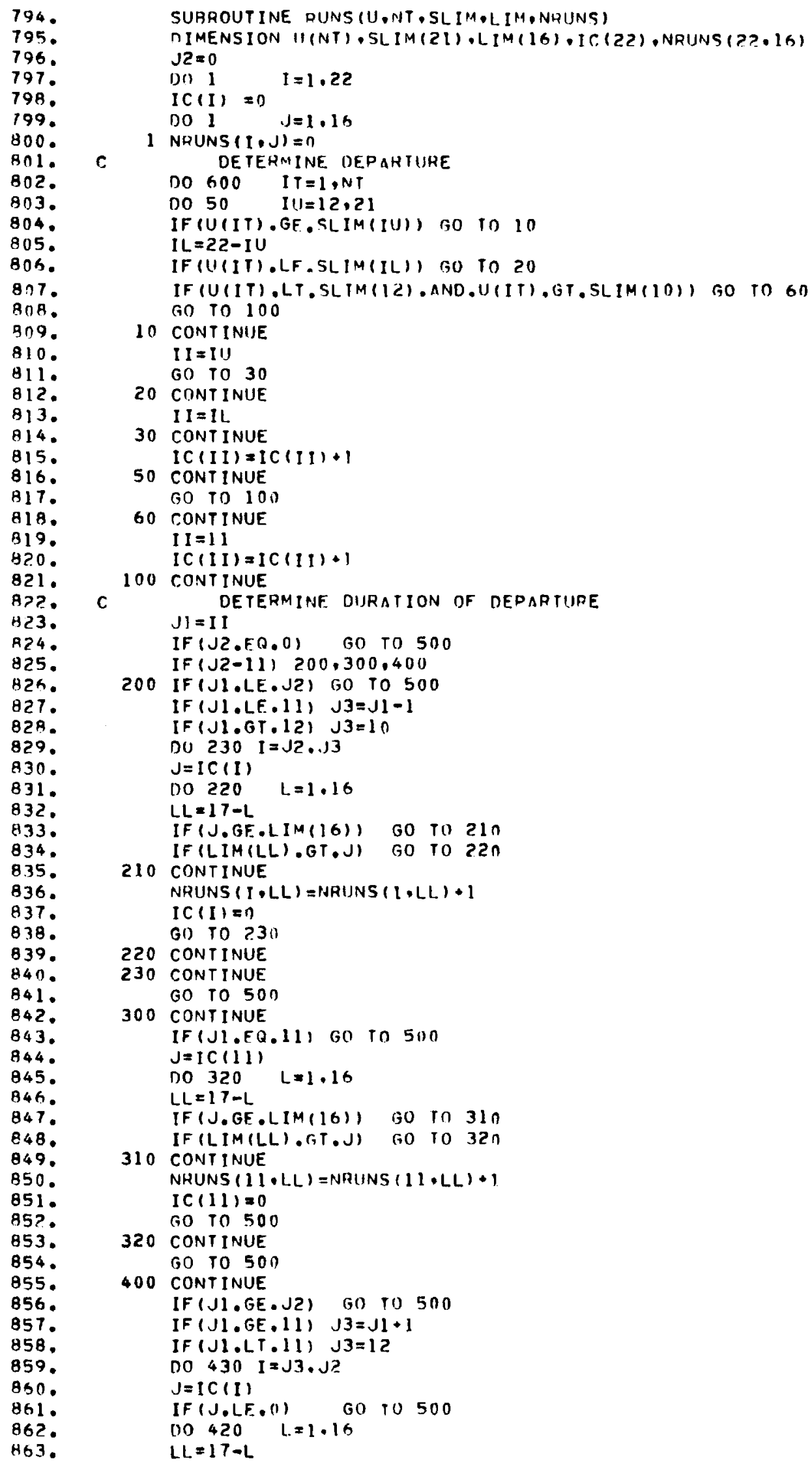




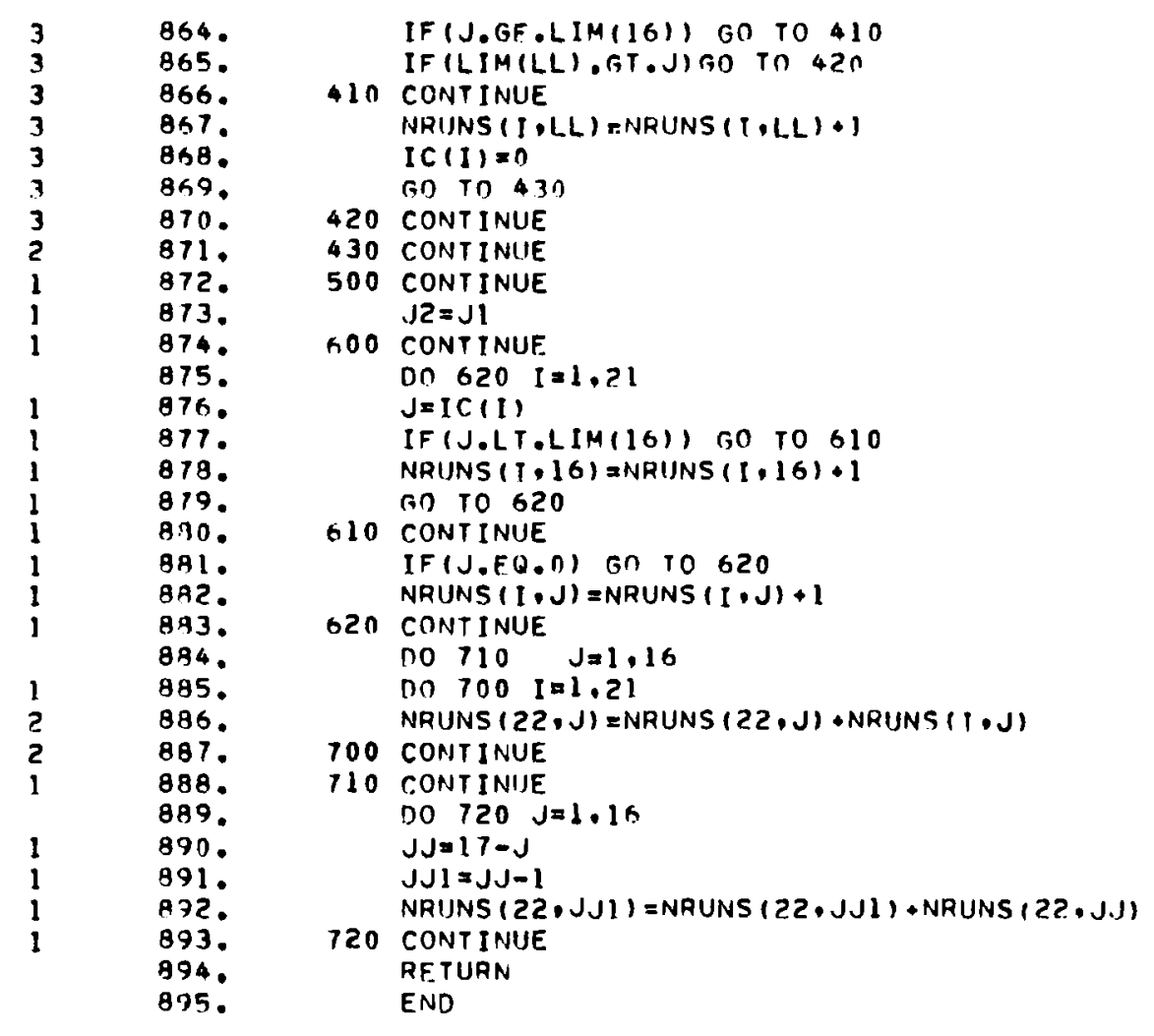


783.

784.

785.

786.

787 .

788.

789.

790.

791 .

792.

793.
SUBROUTINE WAUTOIAMEAN,VAR,ACV,ACOR.NDI DIMENSION ACV (AD) , ACOR (ND)

WRITE $(6,1001)$ AMEAN, VAR

1001 FORMATI/, T20. 'AUTOCOVARIANCES AND AUTO COPRFLATIONSI,TG5,

- MMEAN = ,FB.4.T85. VVARIANCE = .FB.4./1

WPITE $(6,1002)$ (ACV (I),I I N ND)

1002 FORMAT (T10.12F 10.4./T10.12F10.4/)

WRITE $(6,1003)$ (ACOR (I), I=1, ND)

1003 FORMAT (T10,12F10.4./T10,12F10.4/)

RE TURN

END
397.

393.

394.

395.

396.

397.

398.

399.

400 .

401 .

402 .

403.

404.

SUBROUTINE WDATAX (X,NC,NR, IY,AVE,SD,VAR.SKFW,CKUAT)

IIMENSION X(NC,NR) I IY (NA), AVE (NC+1),SD (NC+1), VAR (NC+1), SKEW(NC+1) ,

- CKURT (NC+1) . NAME (5)

MATA NAMF./MEAN', SO', VAR', SKEW', IXURT!'

WRITE $(6,10)(J Y(J), J=1, N R)$, (NAME (I), I $\equiv 1,5)$

10 FORMAT (IH, ?X, I 2, 1915,1X,5(2X,A4)

DO $20 \quad K=1$. NC

WHITE $(6,30)(X(K, I), I=1$, NR), AVE $(K), 50(K), V A R(K), S K F W(K)$, +CKUAT (K)

30 FORMAT (1H.2OF5.2, SF 6.3)

20 CONTINUE

RF. TURN

END

ENI) FTN 1861 IAANK 9428 DHANK

917.

918.

919.

920.

921 .

922.

923.

924.

925.

926.

$9>7$

$9>B$.

SURHOUTINE WDATIY(NC,AVE,SD,VAR, SKEW,CKUIT

DIMENSION AVE $(N C+1), S O(N C+1), V A R(N C+1), 5 K E W(N C+1)$. +CKURT (NC +1) . NAME (5)

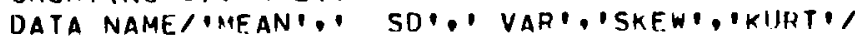

WRITE $(6,10)$ (NAME (I), I =1,5)

10 FORHAT (1HO, MONTH, $5(4 X, A 4))$ $0020 \quad I=1, N C$

WAITE $(6,30)$ I , AVE (I), SO (I), VAG (I), SKEW (I), CKURT (I)

30 FORMAT (1H, I5,5FB.2)

20 CONTINIJE

RETURN

END 


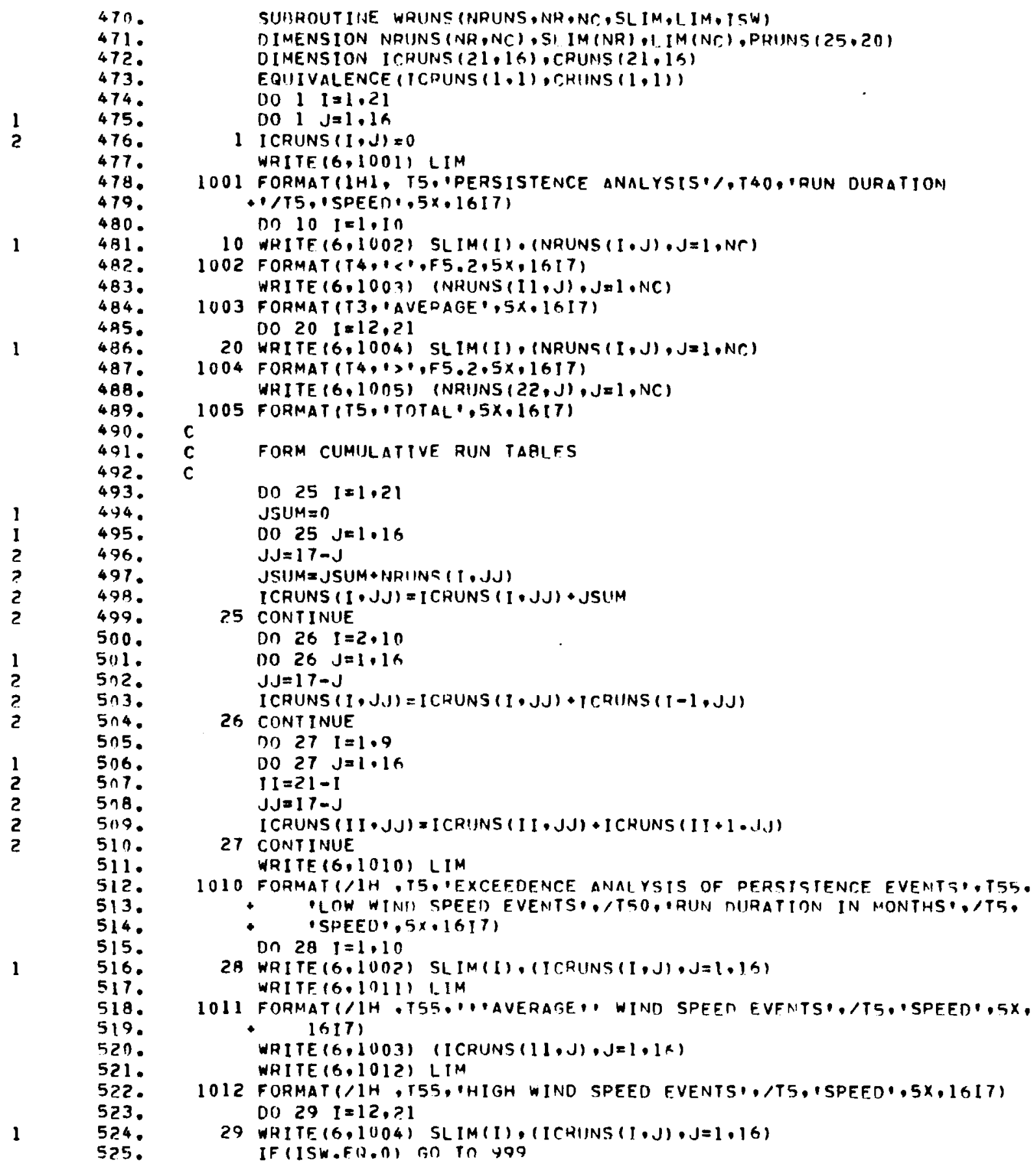




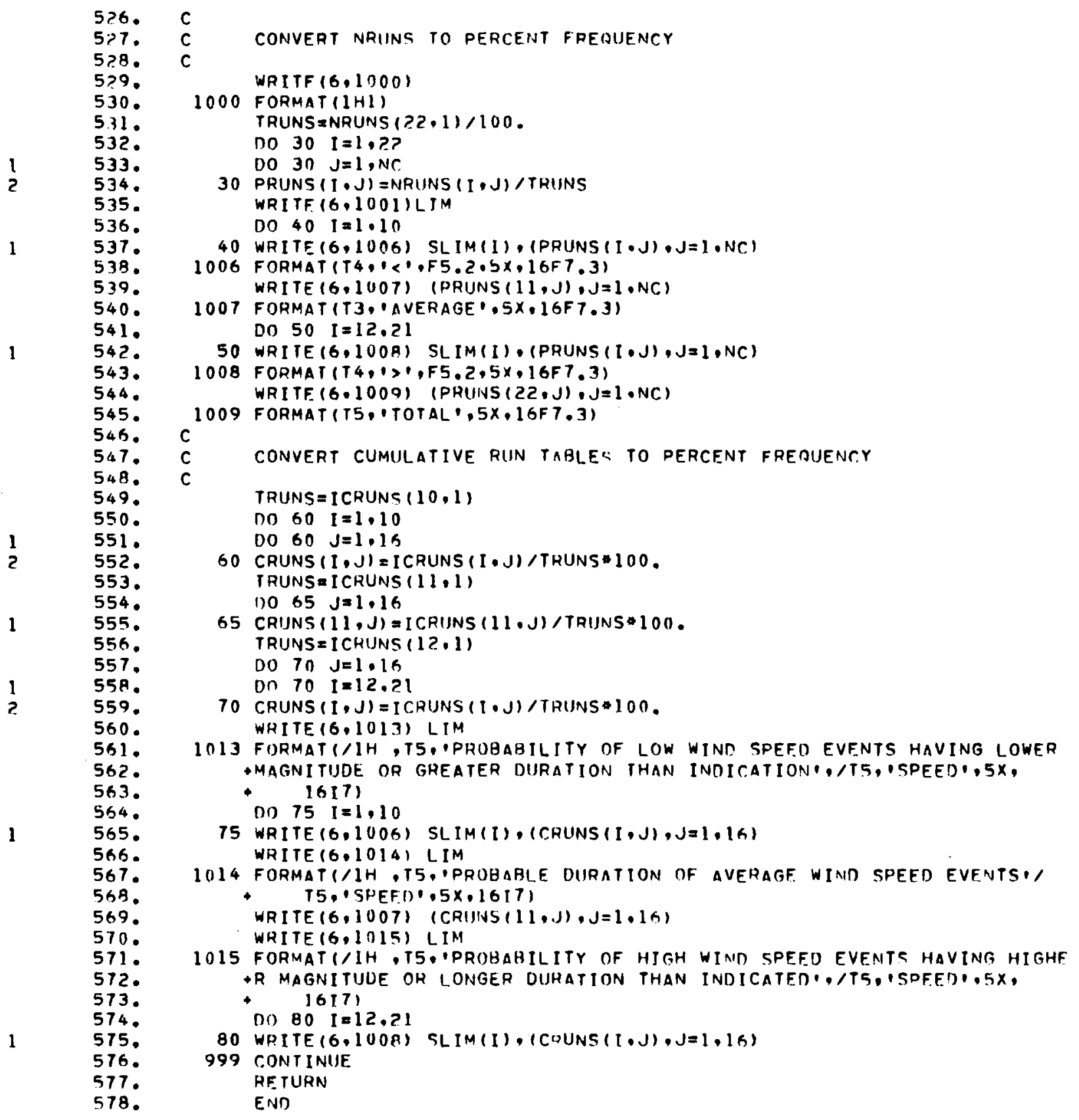




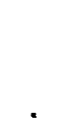


APPENDIX C

WIND SPEED ANALYSIS PROGRAM 


\section{APPENDIX C}

\section{WIND SPEED ANALYSIS PROGRAM}

This appendix presents a program for analys is of wind data to provide the parameters required for wind speed simulation. As listed at the end of the appendix, the program is set to accept data from 1 day every other month, starting in January. It is assumed that the day chosen is about the middle of each month. In our data analysis we used the 15th of each month. We used 24 observations for each day, although the program can be modified to accept fewer observations.

The heart of the analysis is in 4 subroutines: CMTS3, FFITI, FFIT2 and FTAUTO. Table C-I provides brief descriptions of the subroutines. FFITI and FFIT2 are nearly identical. The primary difference between them is in the assumed spacing of the observations. In FFITl it is assumed that the observations occurred at the center of the observation interval, while in FFIT2 it is assumed that the observations occurred at the center of the first half of the observation interval. This difference is apparent in the definition of ANG in the 2 subroutines; lines 268 and 283 in FFITl, and lines 185 and 200 in FFIT2. The reason for the difference is the data used. Data were available for each hour; therefore each observation corresponds to one increment in the angle and can be assumed to occur at the center of the interval. With data available every other month, however, each increment in angle must correspond to 2 months. Thus, the observation or average is assumed to occur at the center of the appropriate month rather than the center of the interval. If the wind observations used had been reported 8 times a day, the period for the Fourier series would have been 8 rather than 24, and the constant subtracted from RI in the definition of ANG would have been $1 / 6,1 / 2$ or $5 / 6$, depending on the time of the observation.

The basic organization of the program is: data input, determination of mean speeds as a function of time of day and month, computation of wind speed standard deviations as a function of the time of day and month, analysis of the standard 
TABLE C-1. Subroutines Used in the Wind Speed Analysis Program

NAME

CMTS3

FFITI

FFIT2

FTAUTO

WDATAX
USE

Computes moments of data in columns of a 2-dimensional array Evaluation of the amplitude and phase angles for seasonal variations of standard deviation and decay constant

deviations, computation of a decay constant for day and an average decay constant for each month, and evaluation of the seasonal variation of the decay constant. The analysis of the standard deviations starts with the determination of a mean and the amplitude and phase angle of its diurnal variations.

Lines 5 through 11 in the program are used for initial data input. It is likely that they will require modifications to accomodate the format of available data. Lines 19 through 39 compute the average wind speeds. If sufficient data were available, this section would generate a table similar to Table 1 that could be used for evaluation of the seasonal and diurnal variation of the mean. The required programming would be similar to the programming used for the analysis of the standard deviations.

The wind speed standard deviations for each time of day and month are computed and printed by the section of the program between lines 43 and 75 . The amplitude and phase angle for the diurnal variations of the standard deviations for each month are computed and printed by 1 ines 83 through 95 . Seasonal variations of the mean and diurnal amplitudes and phase angles of the standard deviaions are determined by the code between 1 ines 96 and 116 . Finally, the section of the program from line 118 through 127 computes parameters for simpler models of the standard deviation.

The last section of the program analyzes the hourly deviations from the mean to determine decay constants. In 1 ines 131 thrugh 138, a decay constant is 
computed for each day's data. These decay constants are analyzed between lines 144 and 151. Initial analysis of the decay constants involves the computation of the moments of the distribution for each month. The seasonal variation of the monthly means is then evaluated, and model parameters are computed and printed.

Tables C-2 and C-3 list the arrays and variables used in the main program and briefiy describe their usage.

TABLE C-2. Arrays Used in the Wind Data Analysis Program

NAME

ASPD

AVLAM

CKURT

HEADER

IYR

SD

SDAMP

SDBAR

SDPHI

SKEW

SPD

VM

XLAM
USE

Average wind speeds (hour, month)

Average decay constant (month)

Coefficient of kurtosis of decay constant distribution (month)

Title or description

Year of the data being analyzed

Standard deviation of the decay constant distribution (month)

Amplitude of the diurnal variation of the standard deviation (month)

Mean standard deviation (month)

Phase angle of the diurnal variation of the standard deviation (month)

Coefficient of skewness of the decay constant distribution (month)

Wind speed observations, also used in computation of the standard deviations (hour, month, year)

Standard deviations of speed (month + annual)

Decay constant (month, year) 
TABLE C-3. Variable Names Used in the Wind Speed Analysis Main Program

ACOR Autocorrelation from FTAUTO

ACV Autocovariance from FTAUTO

COSCO Cosine coefficient for first-order term in Fourier series

$\mathrm{F}$ F-statistic for evaluation of the fit of the Fourier series

GAMA Phase angle for the seasonal variation of the decay constant ( $\gamma$ in Eq. 6)

NHOURS Number of hours per day for which data are being analyzed

NMTHS Number of months per year for which data are being analyzed

NYRS Number of years for which data are being analyzed

RV Residual variance after fitting a Fourier series

SINCO Sine coefficient for first order term in Fourier series

$\mathrm{V}$ Variance returned from FTAUTO, not used

WB Mean returned from FTAUTO, not used

XAMP Amplitude of the variation of the standard deviation

XLAMO Mean decay constant ( $\lambda_{0}$ in Eq. 6 )

XLAMI Amplitude of the seasonal variation of the decay constant $\left(\lambda_{1}\right.$ in Eq. 6)

XPHI Phase angle for the variation of the standard deviation

XVE Mean standard deviation from the fitting of the Fourier series

XX Work space for use of FTAUTO, not used

YY Work space for use of FTAUTO, not used. 


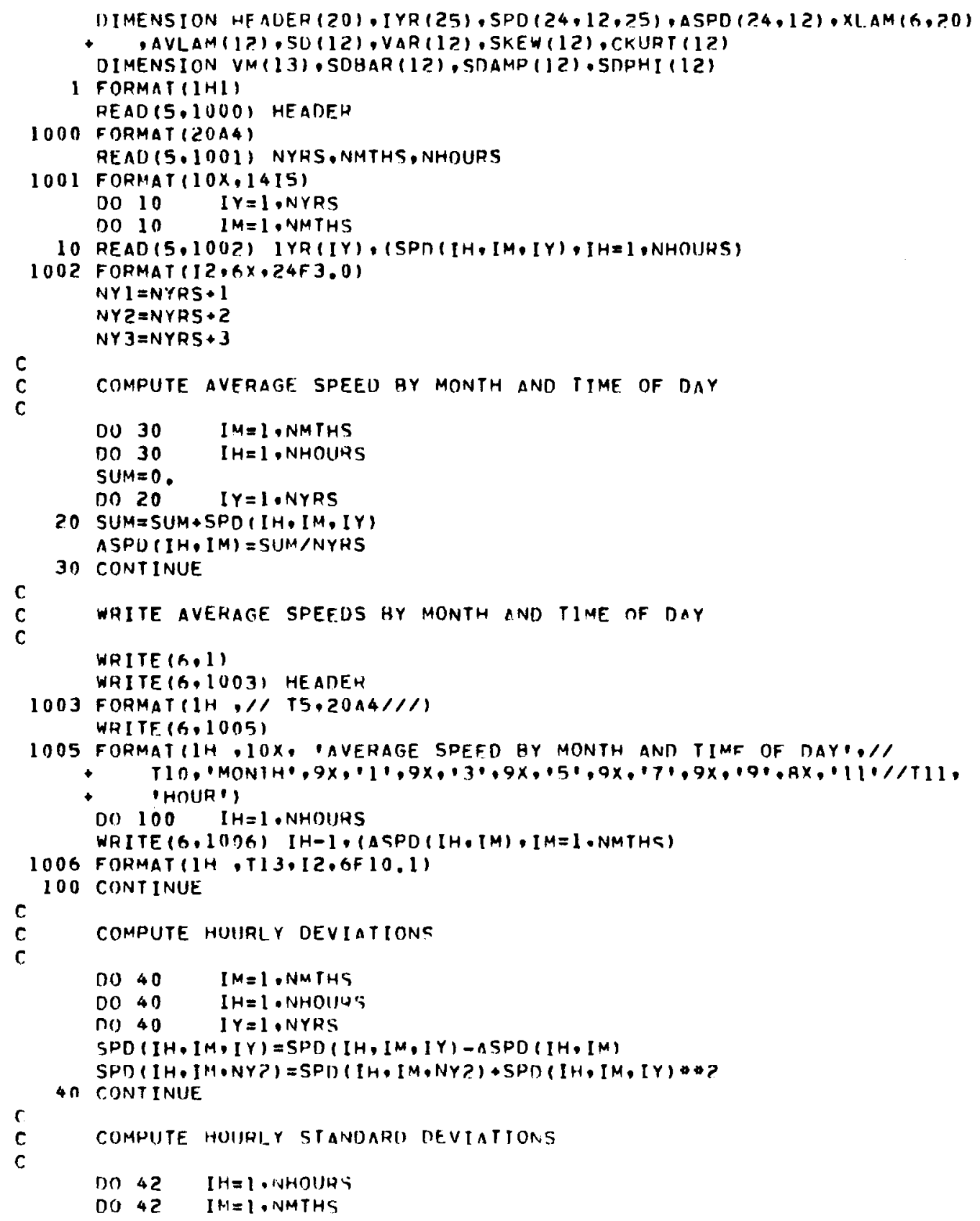




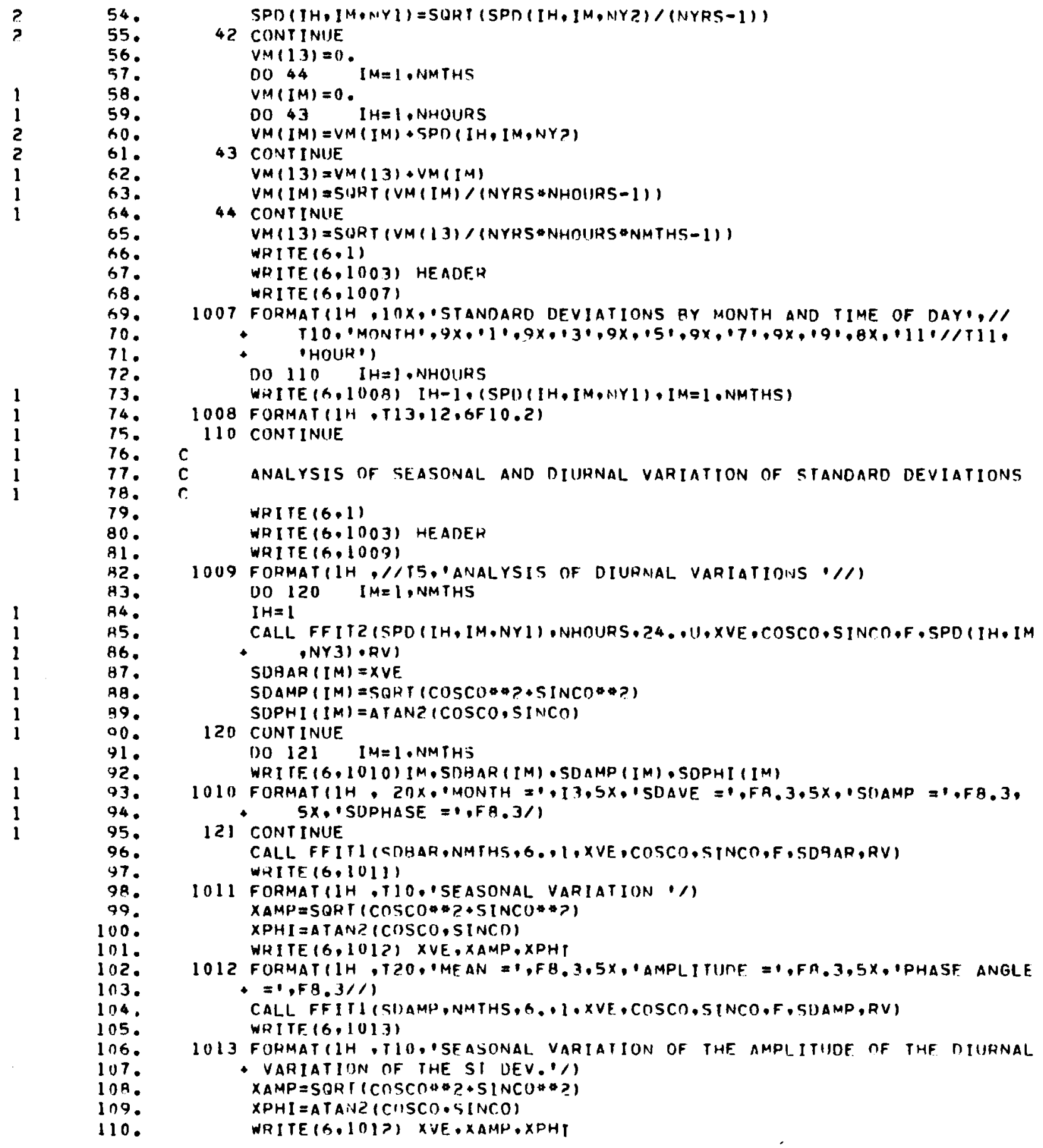


111.

112.

113.

114.

115.

116.

117.

119.

119.

120.

121.

122.

123.

124.

125.

126.

127.

128.

129.

130 .

131.

132.

133.

134.

135 .

136.

137.

130.

139.

140.

141 .

142 .

143.

144.

145.

140.

147.

148 .

149.

150.

151.

152.

WRITE $(6,10] 4)$

1014 FORMAT (1H, T10.'SFASINAL VARIATION OF THE DIURNAL PHASE / )

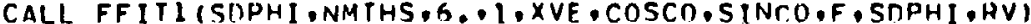

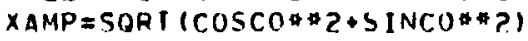

$X P H I=A T A N 2(C \cap S C O, S I N C O)$

WRITE $(6,101 ?)$ XVE, XAMP, XPHI

WRI IE $(6,1)$

WRITE (A.1003) HEAUER

WRITE $(6,1015)$

1015 FORMATIIH ./TS, 'ANALYSIS OF SEASONAL VARIATION OF THE ST DEV.1/I CALL FFITIIVM,NMIHS,G., I, XVE,COSCO.SINCO,F,VM,RVI

$X A M P=S Q R T(C \cap S C O) * 2+S I N C O * ?)$

XPHI =ATANZ (COSCO,SINCO)

WHITE $(6,1012)$ XVE, XAMP, XPHI

WRITE $(6,1016)$ VM(13)

1016 FORMAT(IH ,//TS, ST, DEVIATION WITHOUT SEASONAL OR DIURNAL VARIAT + ION $=1, F 10.3 / 1$

C COMPUTE HOIR-IOH-HOUH CORRELAIJONS

DO $50 \quad$ I $Y=1$, NYRS

DO $50 \quad I M=1$, NMTHS

CALL FTAUTO(SPD (I, IM, IY), NHOURS, $1,0,5, W R, V, A C V, A C O R, X X, Y Y)$

IF (ACOR.GE.0.05) GO TO 45

$X L A M(I M, I Y)=-99.0$

GO TO 50

$45 X \operatorname{LAM}(I M, I Y)=A L O G(A C U R)$

50 CONTINUE

WRITE $(6,1)$

WRITE $(6,100.3)$ HEADER

C

COMPUTE aVERAGE LAMBDA GY mONTH

CALL CMTSJ (XLAM,NMTHS,NYHS, AVLAM, SU,VAR, SKEW, CKURT)

CALL WDATAX (XLAM,NMTHS, NYRS, IYR, AVLAM, SR, VAR, SKEW, CKURT)

CALL FFITI (AVLAM,NMTHS,,., 1 , XVE, COSCO, STNCO,F, AVLAM,RV)

$X L A M \cap=X V E$

GAMA $=A T A N 2(C O S C O, S I N C O)$

$X L A M I=S O R T(C O S C O * 2+S I N C D * 2)$

WRITE $(6.1004)$ XLAMO, XLAMI, GAMA

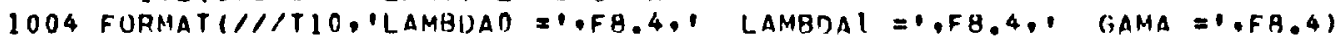
END 


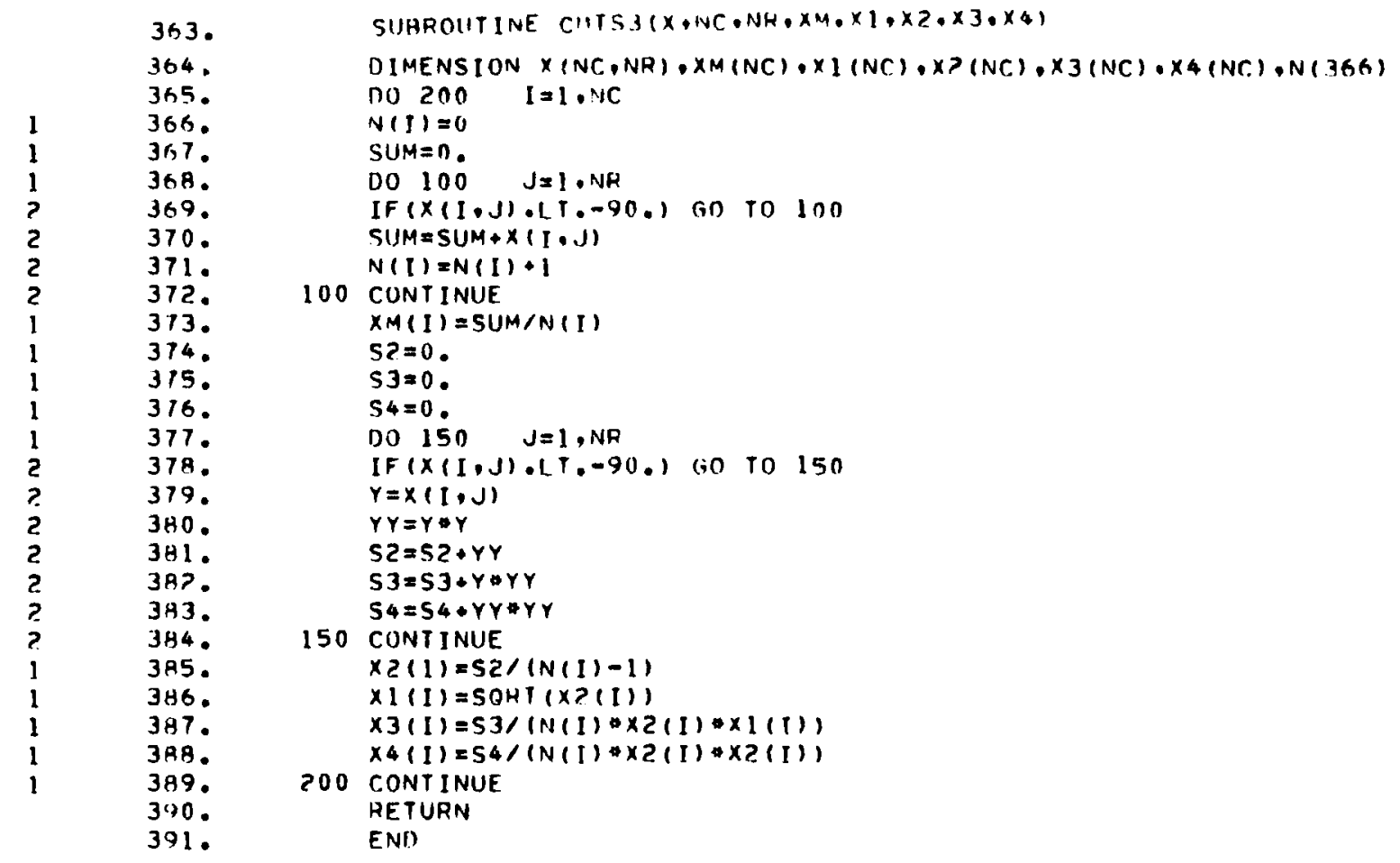




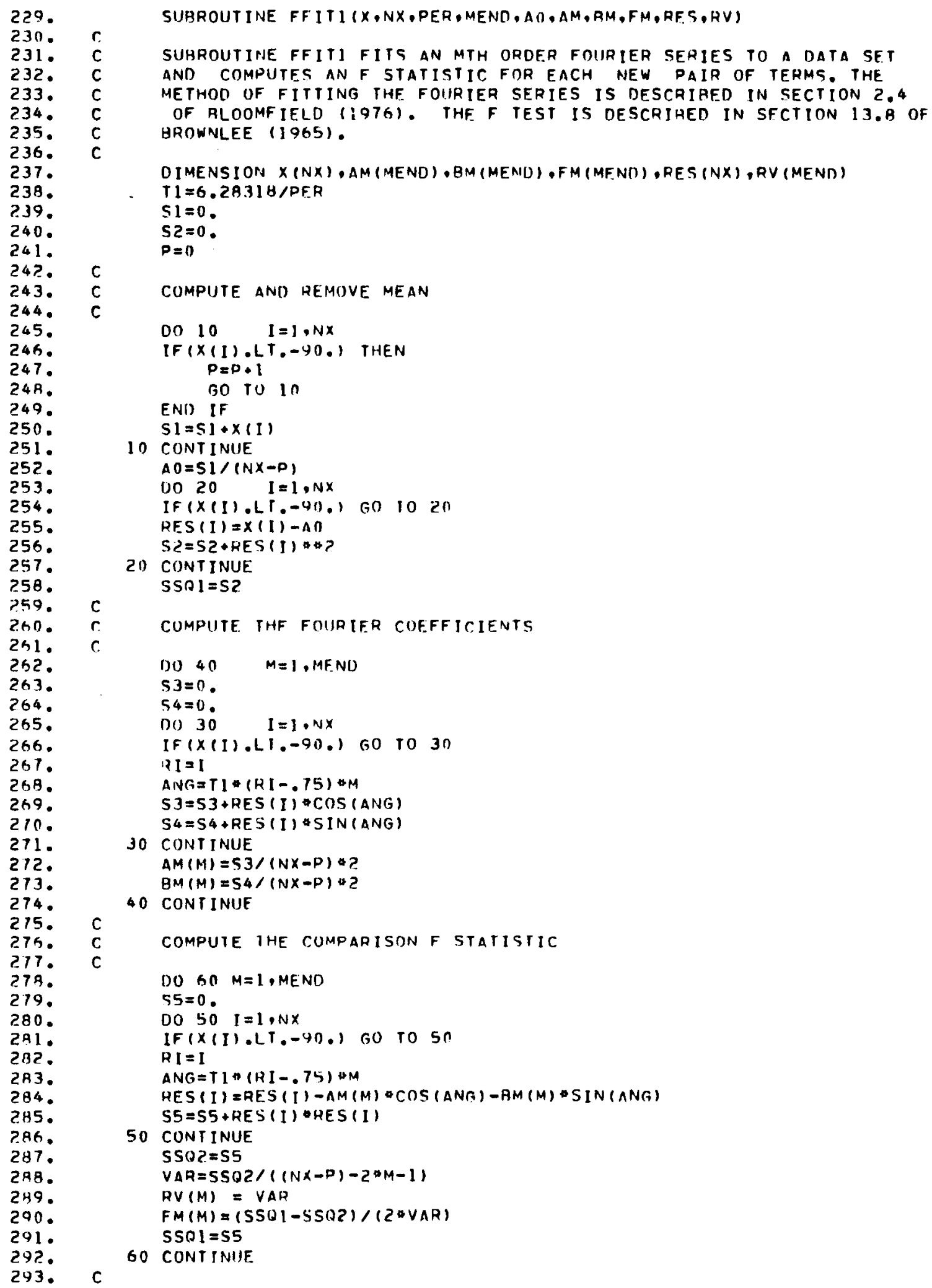




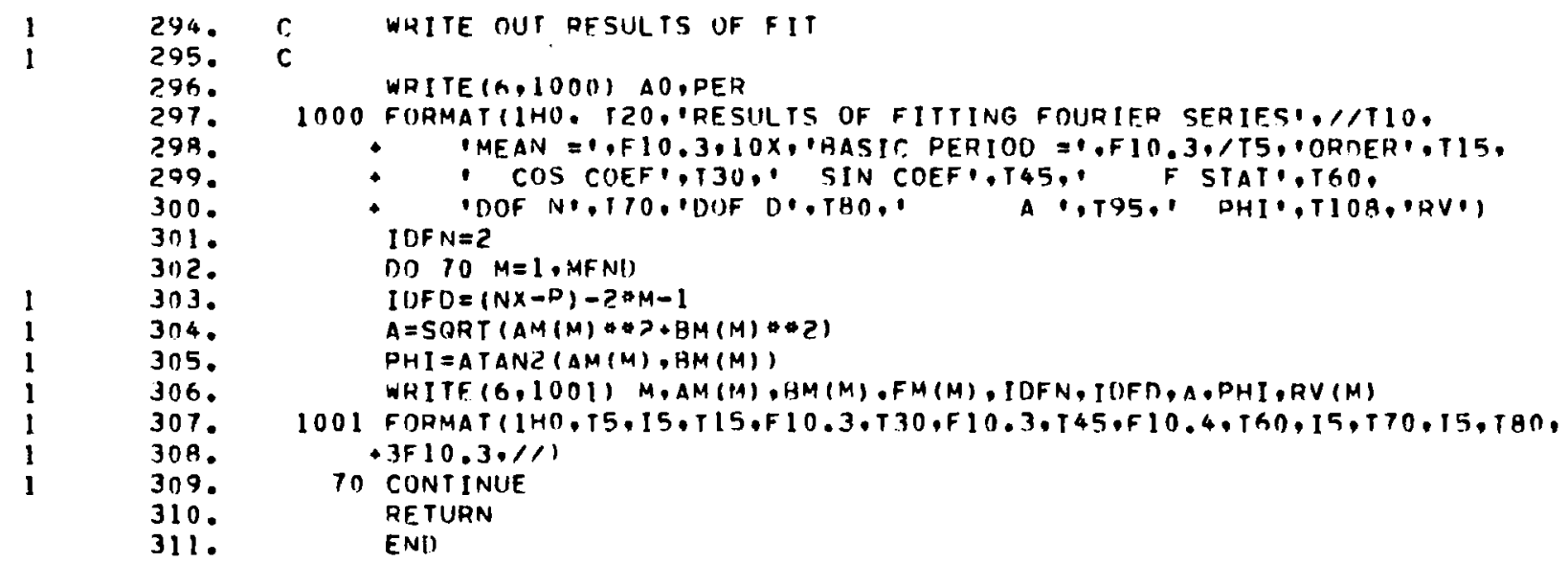




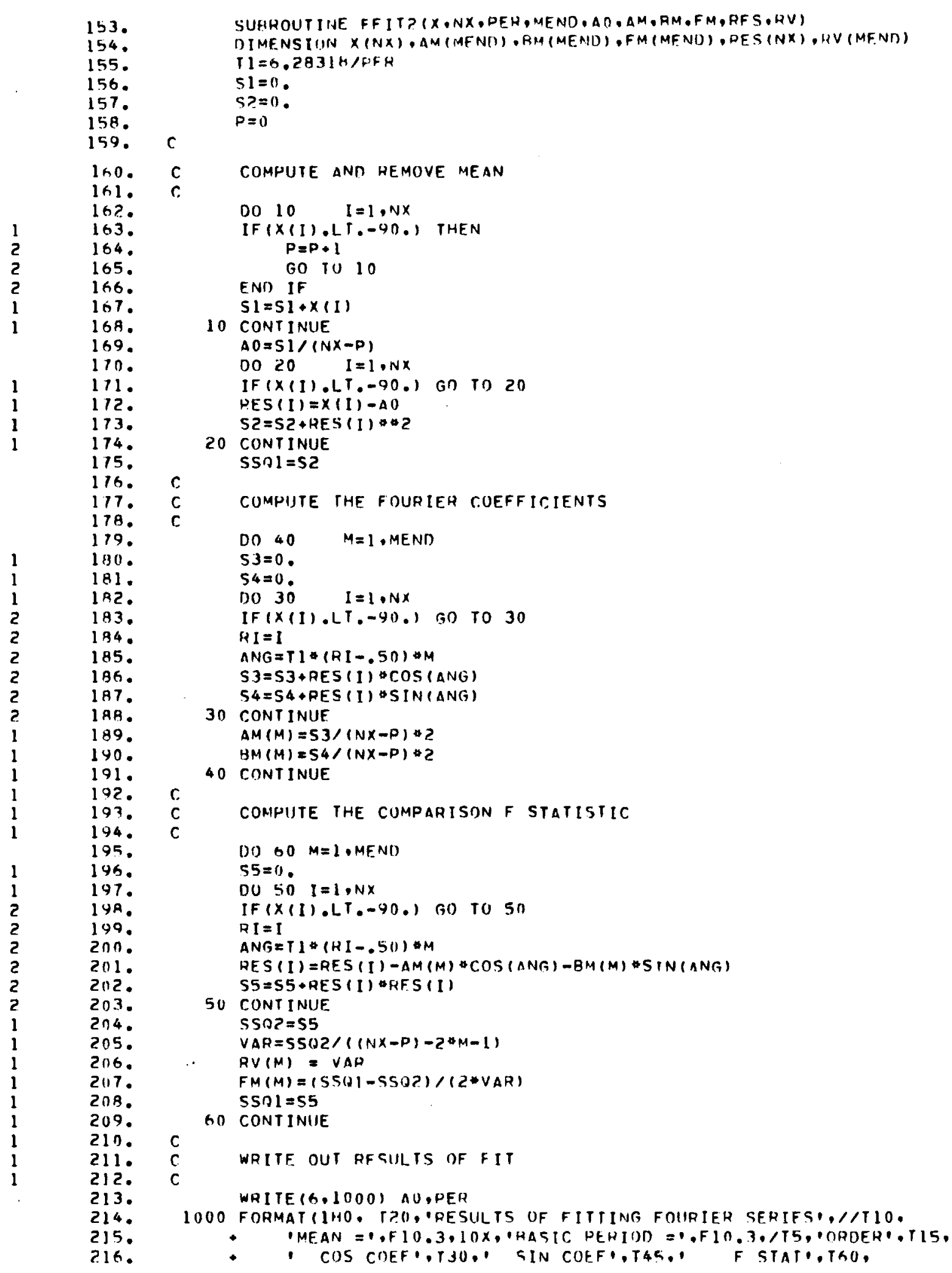




$\begin{array}{ll} & 217 . \\ & 210^{\circ} \\ & 2190^{\circ} \\ 1 & 220^{\circ} \\ 1 & 2210^{\circ} \\ 1 & 2220^{\circ} \\ 1 & 223 . \\ 1 & 224 . \\ 1 & 2250^{\circ} \\ 1 & 226 . \\ & 227 . \\ & 221 .\end{array}$

IDOF NP.TTO, DOF D, TEO,

A '.T95, PHI',TIOR, HAVI) IOFN $=2$ DO $7 n M=1$, MFND

IUFU $=(N X-P)-2 \# M-1$

$A=S D R T(A M(M) * 2+B M(M) * 2)$

$P H I=A T A N Z(\triangle M(M), H M(M))$

WRITE $(6,1001) M, A M(M), B M(M), F M(M), I D F N, I D F D, A, P H I, R V(M)$

1001 FORMAT (1HO,T5, I5,T15,F10.3,T30,F10.3,T45,F10.4,T60,15,T70,I5, TBO. $+3 F 10.3 .111$

10 CONTINUE

RF.TUGN

END 


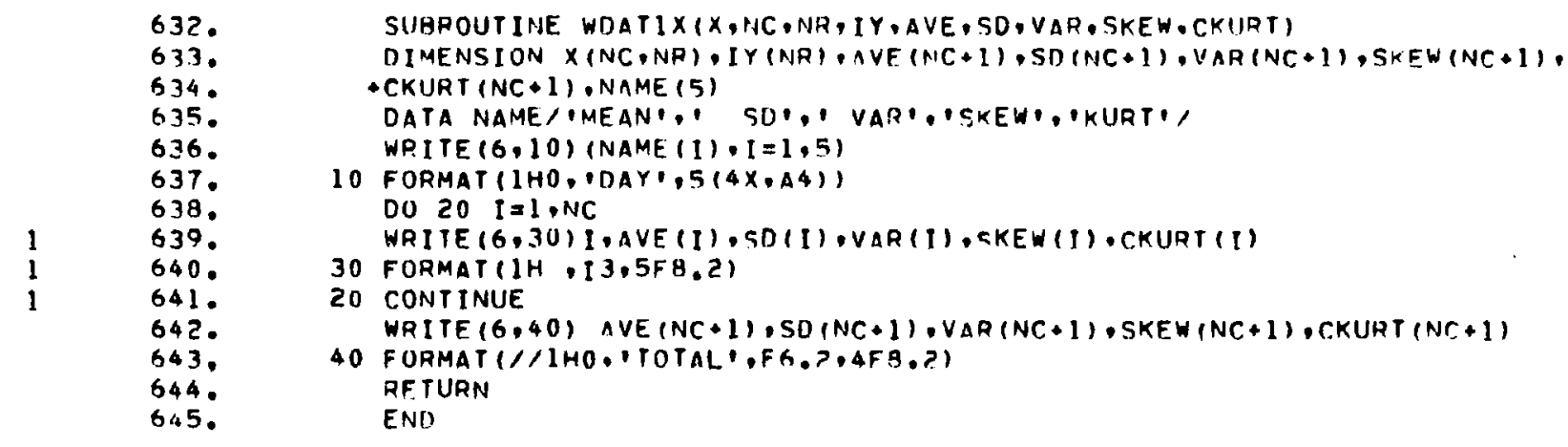




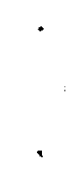




\section{DISTRIBUTION}

No. of

Copies

OFFSITE

A. A. Churm

DOE Chicago Patent Group

9800 S. Cass Avenue

Argonne, IL 60439

D. Ancona

Department of Energy

600 E Street, N.W.

Washington, DC 20545

C. I. Aspliden

Department of Energy

600 E Street, N.W.

Washington, DC 20545

L. V. Divone

Department of Energy

600 E Street, N.W.

Washington, DC 20545

G. P. Tennyson

Department of Energy

Albuquerque Operations Office

P.0. Box 5400

Albuquerque, NM 87110

27 DOE Technical Information Center

Peter Smeallie

AWEA Windletter

1609 Connecticut Avenue N.W.

Washington, DC 20009

T. G. Zambrano

AeroVironment, Inc.

145 Vista Avenue

Pasadena, CA 91107

Clarissa Quinlan

Alaska State Energy Office

338 Denali Street

Anchorage, AK 99501
No. of

Copies
Paut N. Vosburgh

Alcoa Allied Products

Aluminum Company of America

Alcoa Center, PA 15069

Dr. K. C. Spengler

American Meteorological Society

45 Beacon Street

Boston, MA 02108

Tom Gray

American Wind Energy Association

1621 Connecticut Avenue, N.W.

Fifth Floor

Washington, DC 20009

Richard Katzenberg

3100 Highland Place

Washington, DC 20008

E. J. Warchol

Bonneville Power Administration

P.0. Box 3621

Portland, OR 97208

S. J. Hightower

Bureau of Reclamation

Denver Federal Center

Building 67, Code 254

Denver, CO 80225

M. Ginosar/J. Lerner

California Solar Energy Commission

Energy Resources, Conservation and Development Commission

1111 Howe Avenue, Mail Stop 15

Sacramento, CA 95825

Ed Kennell

Clean Energy Products

Wind Power Systems and Components

3534 Bagley N.

Seattle, WA 98103 
E. H. Gilmore

Department of Agriculture Agriculture Research Service Bushland, TX 79012

R. Nolan Clark Department of Agriculture S.W. Great Plains Research Center Bushland, TX 79012

Jay Tappan

Department of Energy

State of Oregon

Labor and Industries Building Room 111

Salem, OR 98310

Dr. Edgar DeMeo

Electric Power Research Institute 3412 Hillview Avenue

Palo Alto, CA 94303

Thomas R. Hiester

Flow Research

21414 68th Avenue, South

Kent, WA 98031

Dr. W. Frost

FWG Associates, Inc.

Route 2, Box 271-A

Tullahoma, TN 37388

R. C. Koch

GEOMET, Inc.

15 First Field Road

Ga ithersburg, MD 20760

James $D$. West

HQ MAC/DEEE

Scott AFB, IL 62225

Gary G. Worley, Maj. USAF

HQ AF-ESC/RDVA

Tyndall AFB, FL 32403
Gary L. Johnson

Electrical Engineering Department

Kansas State University

Manhattan, KN 66506

Dr. J. B. Knox

Lawrence Livermore Laboratory

University of California

P.0. Box 808

Livermore, CA 94550

Abbey Page

Maine Office of Energy Resources

55 Capital

Augusta, ME 04330

Marlatt and Associates

3611 Richmond Drive

Fort Collins, CO 80521

V. F. Garrett

Montana Energy and MHD Research and Development Institute, Inc. P.0. Box 3809

Butte, MT 59701

J. Konigsberg

Montana Energy Office

Capital Station

Helena, MT 59601

Phillip French

NASA Scientific and Technical

Information Facility

P.0. Box 8757

Baltimore/Washington International Airport

Baltimore, MD 21240

R. A. Wolf

NASA Scientific and Technical

Mail Stop 500-201

Cleveland, $\mathrm{OH} \quad 44135$ 
No. of

Copies

M. J. Changery

National Oceanic and Atmospheric Administration

National Climatic Center

Federal Building

Asheville, NC 28801

Ross Bisolinghoff

N.E. Solar Energy Center

70 Memorial Drive

Cambridge, MA 02142

John L. Zimmerman

New England Wind Energy Conversion Services

RDL Box 52E

Moretown, VT 05660

David L. Holmes

Civil Engineering Laboratory NCBC

Port Hueneme, CA 93043

C. F. Chappell

Office of Weather Research and Modification

NOAA-ERL

Boulder, CO 80303

E. W. Hewson/J. E. Wade Oregon State University Corvallis, OR 97331

Charles Toftoy

Project Manager

Raytheon Service Co.

Century Building, Rm. 826

234 Jefferson Davis Highway

Arlington, VA 22202

Terry J. Healy/C. Hansen

Rockwell International

Rocky Flats Plant

P.0. Box 464

Golden, C0 80401
No. of

Copies

E. Kadlec

Sandia Laboratories

Division 5443

P.0. Box 5800

Albuquerque, NM 87115

R. E. Akins

Sandia Laboratories

Division 5443

P.0. Box 5800

Albuquerque, NM 87115

R. M. Traci

Science Applications, Inc.

P.0. Box 2351

La Jolla, CA 92038

W. A. Tolbert, Capt. USAF

SERI Site Office/RTLO

1617 Cole Boulevard

Golden, C0 80401

I. Vas/Roger Taylor

Solar Energy Research Institute

1536 Cole Boulevard

Golden, CO 80401

Dr. C. M. Bhumralkar

Stanford Research Institute, International

Menlo Park, CA 94025

Energy Coordinator Environmental Environmental Resources Section U.S. Army Corps of Engineers

Seattle District

P.0. Box C 3755

Seattle, WA 98124

Bruce Bailey

Atmospheric Sciences Research Center

SUNY Albany - ES 324

Albany, NY 12222 
N. E. Suhs

Tennessee Valley Authority

1360 Commerce Union Bank Building

Chattanooga, TN 37401

Dr. P. Yen

University of Hawaij at Monoa

240 Holmes Hall

2540 Dole Street

Honolulu, HI 96822

Ahsan Kareem

Wind Tunnel Laboratory

Department of Civil Engineering

University of Houston

Houston, TX 77004

Dr. N. K. Wagner

Dept. of Civil Engineering

University of Texas

Austin, TX 78712

Dr. Michael Garstang

University of Virginia

Charlottesville, VA 22903

David Kapus

Washington State Division of

Engineering and Architecture

106 Maple Drive

O1ympia, WA 98504

Susan Hosch

Washington State Energy Office

400 E Union Avenue, lst Floor

Olympia, WA 98504

John Young

Washington Public Power Supply

System

P.0. Box 968

Richland, WA 99352

S. R. Epur/G. D. Thomann

Wichita State University

P.0. Box 44

Wichita, KS 67208
Farrell Smith Seiler

Wind Energy Report

Box 14 - 104 S. Village Avenue

Rockville Centre, NY 11571

Dr. V. Barros

28 De Julio 28

9120 Puerto Madryn

Chulret

R. ARGENTINA

Dr. 011 e Ljungstrom

FFA, The Aeronautical Research Institute

Forskningsstationen i Stockholm

Drottning Kristinas Vag 47

S-114 29 Stockholm, SWEDEN

R. B. Lawford

Fisheries \& Environment

25 St. Clair Avenue East

Toronto, CANADA M4T 1M2

R. J. Templin

National Research Council of Canada

National Aeronautical

Establ ishment

M-2 Montreal Road

Ottawa, Ontario KIA OR6

CANADA

P. W. Blakely

New Zealand Electricity

Rutherford House

Lambton Quay

We 11 ington, NEW ZEALAND

D. Lindley

Taylor Woodrow Construction, Limited

Taywood House

345 Ruislip Road

Southha 11

Middlesex UBI 2QX

ENGLAND 
No. of

Copies

Richard L. Berry

Atmospheric Environment

4905 Dufferin Street

Downsview, Ontario

M3H 5 T4

CANADA

ONSITE

DOE Richland Operations Office

P.0. Box 550

Richland, WA 99352

H. E. Ransom

56 Pacific Northwest Laboratory

Battelle Boulevard

Richland, WA 99352

G. F. Athey

M. Y. Ballinger

W. R. Barchet

J. C. Barnard

J. W. Buck

J. R. Connell

J. C. Doran

R. L. Drake

C. E. Elderkin

D. L. Elliott

R. L. George

D. L. Hadley

S. K. Heflick

V. K. Hopkins (15)

A. H. Miller

E. L. Owczarski

W. T. Pennell

D. C. Powell

J. J. Praino

J. V. Ramsdell (10)

D. S. Renné

J. M. Reeder

W. F. Sandusky

H. L. Wegley

L. L. Wendel 1

R. K. Woodruff

Technical Information - Library (5)

Publishing Coordination (2) 


\section{.}

